NBER WORKING PAPER SERIES

\title{
INTERNATIONAL FINANCIAL ADJUSTMENT IN A CANONICAL OPEN ECONOMY GROWTH MODEL
}

\author{
Richard H. Clarida \\ Ildikó Magyari
}

Working Paper 22758

http://www.nber.org/papers/w22758

\author{
NATIONAL BUREAU OF ECONOMIC RESEARCH \\ 1050 Massachusetts Avenue \\ Cambridge, MA 02138 \\ October 2016
}

The views expressed herein are those of the authors and do not necessarily reflect the views of the National Bureau of Economic Research.

NBER working papers are circulated for discussion and comment purposes. They have not been peer-reviewed or been subject to the review by the NBER Board of Directors that accompanies official NBER publications.

(C) 2016 by Richard H. Clarida and Ildikó Magyari. All rights reserved. Short sections of text, not to exceed two paragraphs, may be quoted without explicit permission provided that full credit, including $(\odot$ notice, is given to the source. 
International Financial Adjustment in a Canonical Open Economy Growth Model

Richard H. Clarida and Ildikó Magyari

NBER Working Paper No. 22758

October 2016

JEL No. F3,F32,F41

\begin{abstract}
$\underline{\text { ABSTRACT }}$
Gourinchas and Rey (2007) have shown that international financial adjustment (IFA) in the path of expected future returns on a country's international investment portfolio can complement or even substitute for the traditional adjustment channel via a narrowing of country's current account imbalance. In their paper, GR derive this result using a log linearization of a net foreign asset accumulation identity without reference to any specific theoretical model of IFA in expected foreign asset returns or the real exchange rate. In this paper we calibrate the importance of IFA in a standard open economy growth model (Schmitt-Grohe and Uribe, 2003) with a well-defined steady level of foreign liabilities. In this model there is a country specific credit spread which varies as a function of the ratio of foreign liabilities to GDP. We find that allowing for an IFA channel results in a very rapid converge of the current account to its steady state (relative to the no IFA case) so that most of the time that the country is adjusting, all the adjustment is via the IFA channel of forecastable changes in the costs of servicing debt and in the appreciation real exchange rate. By contrast, in the no IFA case, current account adjustment by construction does all the work and current account adjustment is much slower.
\end{abstract}

\author{
Richard H. Clarida \\ Columbia University \\ 420 West 118th Street \\ Room 1111, IAB \\ New York, NY 10027 \\ and NBER \\ rhc2@columbia.edu \\ Ildikó Magyari \\ Columbia University \\ 420 West 118 th Street \\ Dept. of Economics \\ New York, NY 10027 POSTAL ADDRESS HERE \\ ildiko.magyari@columbia.edu
}




\section{International Financial Adjustment in a Canonical Open Economy Growth Model ${ }^{1}$}

\author{
Richard H. Clarida \\ Columbia University and NBER
}

Ildikó Magyari

Columbia University

October 11, 2016

\section{Introduction}

In influential work, Gourinchas and Rey (2007) have shown that international financial adjustment (IFA) in the expected returns on a country's international investment portfolio as well as the expected path of the real exchange rate can complement or even substitute for the traditional adjustment channel via a narrowing of country's 'unsustainable' current account imbalance. In their paper, GR derive this result using a log linearization of a net foreign asset accumulation identity without reference to any specific theoretical model of international financial adjustment in expected foreign asset returns or the real exchange rate. In this paper we calibrate the importance of IFA in a standard open economy growth model (Schmitt-Grohe and Uribe, 2003) with a well-defined steady level of foreign liabilities. In this model there is a country specific credit spread which varies as a function of the ratio of foreign liabilities to GDP.

We study a perfect foresight version of the model so that we can characterize the global dynamic adjustment in net foreign assets, the endogenous cost of debt service, and the path of the real exchange rate. This is important, because in this model, in a neighborhood of the steady state, IFA is not very important. However, away from the steady state - we look at simulations in which the initial stock of foreign debt is 10 percent above its steady state ratio to GDP and the initial capital stock is 10 percent below its steady state ratio to GDP IFA is very important. In fact in our baseline simulation in which we calibrate the elasticity of the country credit spread to the debt to GDP ratio based on plausible empirical estimates from the literature as well as our own estimates, we find that allowing for an IFA channel

\footnotetext{
${ }^{1}$ Richard H. Clarida: rhc2@columbia.edu; Ildikó Magyari: im2348@columbia.edu
} 
results in a very rapid converge of the current account to its steady state (relative to the no IFA case) so that most of the time that the country is adjusting, all the adjustment is via forecastable changes in the costs of servicing debt and in the appreciation real exchange rate and none of the adjustment is in the current account. By contrast, in the no IFA case, current account adjustment by construction does all the work and current account adjustment is much slower. Finally we show that IFA adjustment via the real exchange rate can be important even if forecastable changes in the cost of debt service are not.

\section{Channels of the small open economy's international financial adjustment}

Countries can stabilize their net international investment position through two channels: the trade channel and the financial channel. As net foreign liabilities today must be compensated by trade surpluses in the future, the trade channel contributes to the external adjustment of the country by the adjustment in the value of the goods and services that the country imports or exports. However, the forecastable increase in the real returns on the net foreign assets or forecastable decrease in the real cost of servicing net international liabilities (i.e. the financial channel) can substitute for adjustment in trade flows. Thus, the financial channel contributes to the external adjustment of the country through the adjustment in real interest rates and real exchange rates.

To illustrate this formally, we first derive a log-linearized version of the balance of payment accounting identity with gross international liability position, $l_{t}$, and zero gross international asset position $^{2}$ :

$$
l_{t}=\rho\left(l_{t+1}-r_{t+1}\right)+(1-\rho) n x_{t}
$$

where $r_{t+1}$ is the interest payed on gross international liabilities, $\rho$ is the discount rate and $n x_{t}$ are net exports. Iterating forward on expression (1), the gross liability position of the country becomes:

$$
l_{t}=-\sum_{j=1}^{\infty} \rho^{j} r_{t+j}+n x_{t}+\sum_{j=1}^{\infty} \rho^{j} \Delta n x_{t+j}
$$

where the first term is the discounted sum of future returns, which captures all the international adjustments through the financial channel, the second and third terms are the discounted sum of future changes in the net exports, which captures the adjustment through the trade channel.

There is little empirical evidence on how important these channels are in countries'

\footnotetext{
${ }^{2}$ Section 1 of the Theory Appendix outlines the derivation of this log-linearized identity.
} 
international adjustment. Gourinchas and Rey (2007) find that about 27\% of the cyclical

international adjustment of the United States has been realized through the financial channel, primarily through a forecastable adjustment in the real exchange rate. But we do not have empirical evidence in the case of other countries such as Japan, UK or the Euro Zone. Moreover, we do not have any evidence on how important role these channels play in the case of emerging economies. Intuitively, we can expect that the financial channel may play an even more important role in the case of developing and emerging economies than it does in the case of developed ones, especially in the case of the emerging economies with larger external debt position.

The reduced form balance of payment identity allows for quantifying the size of the two channels. However, it does not give any insight about how the real interest rate and real exchange rate channel interact with the trade channel. Moreover, as it is an identity and there is no micro-foundation behind it, it is not suitable for studying the mechanisms through which the trade and financial channels operate. Thus, the challenge is to find a theoretical machinery that rationalizes this resource constraint.

The small open economy real business cycle model rationalizes the intertemporal resource constraint in (1). This class of models augmented with endogenous interest and exchange rates provides a simple and elegant laboratory to understand how the financial and trade channels operate in an intertemporal framework that pins down the equilibrium path of the real cost of servicing international debt and the real cost of borrowing from the international markets. This framework also allows for studying the interaction between the trade and financial channel, and sheds light on the mechanism through which these channels operate.

In this paper, we focus on emerging economies. We write down two versions of the small open economy real business cycle model that rationalizes the balance of payment accounting identity, thus quantifying the relative importance of the two channels becomes possible. Moreover, these models provide a micro-foundation for studying the way these channels operate, the way they interact with each other and the mechanism through which they operate. We present these models in the next section.

\section{Theoretical framework}

In this section, we consider two versions of the small open economy real business cycle model that rationalizes the intertemporal resource constraint. This model augmented with endogenous interest rate, respectively with real exchange rate provides a simple and elegant laboratory to study the relative importance of the trade and financial channels in the external adjustment process of the small open economy, while also allowing for an interaction between 
these two channels. It also allows for shedding light on the potential mechanism through which these channels operate.

First, we consider the non-stochastic version of the small open economy real business cycle model augmented with the debt dependent interest rate. While writing down this model, we closely follow the functional form assumptions made by Schmitt-Grohe and Uribe (2003). In this framework we can study the relative importance of the trade and real interest rate channels in the external adjustment of the small open economy.

As a next step, we zoom into the financial channel. We consider a version of the small open economy real business cycle model that allows us to disentangle the real interest rate and real exchange rate channels. In particular, we write down a non-stochastic version of the small open economy real business cycle model with debt dependent interest rate that is augmented with tradables and non-tradables sectors. In this model, the price of tradable relative to non-tradable pins down the real exchange rate. This framework allows us to study the relative importance of the trade, real exchange rate and real interest rate channels in the external adjustment of the small open economy. Thus, the main advantage of this framework relative to the previous one is that it allows for the decomposition of the financial channel into two components: the real exchange rate and the real interest rate channels.

\subsection{The small open economy RBC model with external interest rate}

\subsubsection{The setup}

We start by assuming that the country is a small open economy populated by a large number of identical households. We assume that the representative household's per-period utility, $U(\cdot)$, is derived from consumption, $c_{t}$, and hours worked, $h_{t}$. Following the RBC literature on small open economies, we assume that the representative household's preference is modeled as GHH (Greenwood et al., 1988). This implies the following functional form for $U(\cdot)$ :

$$
U\left(C_{t}, h_{t}\right)=\frac{\left(C_{t}-h_{t}^{\omega} / \omega\right)^{1-\sigma}}{1-\sigma}
$$

where $\omega$ and $\sigma$ are utility parameters capturing the elasticity of substitution between consumption and hours worked, respectively the elasticity of substitution of the consumption today with consumption tomorrow. Thus, the discounted sum of per-period utility is given by:

$$
\max \sum_{t=0}^{\infty} \beta^{t} U\left(c_{t}, h_{t}\right)
$$


where $\beta \in(0,1)$ is the discount factor.

The representative household's per-period budget constraint is:

$$
d_{t+1}=\left(1+r_{t}\left(d_{t+1}\right)\right) d_{t}+c_{t}+i_{t}-y_{t}+\phi\left(k_{t+1}-k_{t}\right)
$$

where $d_{t}$ is the stock of debt that the small open economy accumulates up until period $t-1$ by borrowing in the international financial markets, $d_{t+1}$ is the stock of external debt that consists of the stock of debt at the end of period $t$-1 plus the new loans contracted by the small open economy on the international markets in the $t^{\text {th }}$ period; $i_{t}$ denotes investment in period $t ; y_{t}$ is the domestic output in period $t$; and $k_{t}$ is the stock of physical capital at the end of period $t-1$.

The interest rate at which the small open economy borrows on the international markets in period $t$ is $r_{t}$. Following Schmitt-Grohe and Uribe $(2003)^{3}$, we assume that the domestic interest rate is the sum of the world interest rate on the international financial markets, $r^{*}$, and the spread that the small open economy pays upon borrowing on these markets. We assume that the country spread is endogenous. Its size depends on the deviation of the small open economy's debt to output ratio, $\frac{d_{t+1}}{y_{t}}$, from its steady state value, $\widetilde{d}$, and the debt elasticity of the domestic interest, captured by parameter $\psi$ :

$$
r\left(d_{t+1}\right)=r^{*}+\psi\left(\exp \left(\frac{d_{t+1}}{y_{t}}-\tilde{d}\right)\right)
$$

These assumptions on the functional form of the domestic real interest rate imply that the cost of borrowing that the small open economy faces on the international markets is increasing in the world interest rate, the debt elasticity of the country spread (i.e. the more sensitive is the country spread to fluctuations in the external debt position of the country relative to its steady state), and the deviation of the debt to output ratio relative to its steady state.

Function $\phi(\cdot)$ is the capital adjustment cost that the representative consumer acquires for each unit of investment made in physical capital ${ }^{4}$. Following Schmitt-Grohe and Uribe (2003), we assume that the capital adjustment cost is modeled as a quadratic function of the current and past capital stock levels, and it captures the fact that faster adjustments in

\footnotetext{
${ }^{3}$ Technically, this functional form assumption ensures that the non-stochastic steady state of the model is independent of the initial conditions, and thus it is stationary.

${ }^{4}$ Technically, the role of this capital adjustment cost in the small open economy RBC model is to dampen the large volatility of investment in response to changes in the interest rate. The functional form is chosen such that in steady state the adjustment cost is zero, as we assume that $\phi(0)=\phi^{\prime}(0)=0$, and thus the marginal product of capital matches exactly the interest rate.
} 
the capital stock are more expensive:

$$
\Phi\left(k_{t+1}, k_{t}\right)=\frac{\phi}{2}\left(k_{t+1}-k_{t}\right)^{2}
$$

We assume that capital depreciates at rate $\delta \in(0,1)$. Thus, the stock of physical capital owned by the representative household at time $t$ is the stock at the end of period $t$ - 1 , net of depreciation, plus the value of the new investment, captured by the following capital accumulation equation:

$$
k_{t+1}=(1-\delta) k_{t}+i_{t}
$$

Output is produced by hiring labor, $h_{t}$, and using physical capital, $k_{t}$, in order to produce consumption goods, $y_{t}$, based on a neoclassical production technology:

$$
y_{t}=F\left(k_{t}, h_{t}\right)
$$

We assume that the production function is Cobb-Douglas with $\alpha$ being the share of capitals in total output:

$$
F\left(k_{t}, h_{t}\right)=k_{t}^{\alpha} h_{t}^{1-\alpha}
$$

\subsubsection{Non-linear equilibrium conditions}

The representative household maximizes lifetime utility (4) subject to the budget constraint

in (5), and chooses the optimal path of $\left\{c_{t}, h_{t}, i_{t}, y_{t}, k_{t+1}, d_{t+1}, \lambda_{t}\right\}_{t=0}^{\infty}$. Thus, the following system of nonlinear equations describes the optimal dynamics of the model variables $\left\{c_{t}, h_{t}, i_{t}, y_{t}, k_{t+1}, d_{t+1}, \lambda_{t}, r_{t}\right\}_{t=0}^{\infty}$ :

$$
\begin{gathered}
\left(c_{t}-h_{t}^{\omega} / \omega\right)^{-\sigma}=\lambda_{t} \\
h_{t}^{\omega-1}\left(c_{t}-h_{t}^{\omega} / \omega\right)^{-\sigma}=\lambda_{t}(1-\alpha) k_{t}^{\alpha} h_{t}^{-\alpha} \\
\lambda_{t}=\beta \lambda_{t+1}\left[1+r\left(d_{t+1}\right)\right] \\
\lambda_{t}\left[1+\phi\left(k_{t+1}-k_{t}\right)\right]=\beta \lambda_{t+1}\left[1-\delta+\phi\left(k_{t+2}-k_{t+1}\right)+\alpha\left(\frac{k_{t+1}}{h_{t+1}}\right)^{\alpha-1}\right] \\
d_{t+1}=\left(1+r_{t}\left(d_{t+1}\right)\right) d_{t}+c_{t}+k_{t+1}-(1-\delta) k_{t}-k_{t}^{\alpha} h_{t}^{1-\alpha}+\frac{\phi}{2}\left(k_{t+1}-k_{t}\right)^{2}
\end{gathered}
$$




$$
\begin{gathered}
y_{t}=k_{t}^{\alpha} h_{t}^{1-\alpha} \\
k_{t+1}=(1-\delta) k_{t}+i_{t} \\
r\left(d_{t+1}\right)=r^{*}+\psi\left(\exp \left(\frac{d_{t+1}}{y_{t}}-\tilde{d}\right)\right)
\end{gathered}
$$

\subsection{The small open economy RBC model with external interest rate and real exchange rate}

\subsubsection{The setup}

In this version of the model, we assume that the representative household's utility, $U(\cdot)$, is derived from consumption of tradable goods, $c_{t}$, consumption of non-tradable goods $c_{n t}$, and hours worked, $h_{t}$. We assume that tradable and non-tradables consumption is aggregated into total consumption in the household's utility in a Cobb-Douglas way, with $b$ being the share of non-tradable in total consumption, while consumption and hours worked are aggregated by a CES function as in the previous version of the model:

$$
U\left(c_{n t}, c_{t}, h_{t}\right)=\frac{\left(c_{n t}^{b} c_{t}^{1-b}-h_{t}^{\omega} / \omega\right)^{1-\sigma}}{1-\sigma}
$$

Thus, the discounted sum of per-period utility is given by:

$$
\max \sum_{t=0}^{\infty} \beta^{t} U\left(c_{n t}, c_{t}, h_{t}\right)
$$

where $\beta \in(0,1)$ is the discount factor.

The representative household's per-period budget constraint evaluated at the price of tradables relative to the non-tradables is as follows:

$$
p_{t} d_{t+1}=p_{t}\left(1+r_{t}\left(d_{t+1}\right)\right) d_{t}+p_{t} c_{t}+c_{n t}+p_{t} i_{t}-y_{t}+p_{t} \frac{\phi}{2}\left(k_{t+1}-k_{t}\right)^{2}
$$

By comparing equation (20) with equation (5), one can easily notice that the only difference between the two versions of the model is given by the assumption on the two sectors of the economy, tradables and non-tradables. We need these assumptions in order to pin down the equilibrium path of the real exchange rate defined as the price of tradables relative to non-tradables ${ }^{5}$.

\footnotetext{
${ }^{5}$ Based on this definition of the relative price, the real exchange rate is defined as the price of one unit
} 
The total output in this economy is given by the sum of the output produced by the two sectors of the economy:

$$
y_{t}=N_{t}+p_{t} T_{t}
$$

We assume that the nature of the technology in the tradable sector is Cobb-Douglas, and this sector uses capital and labor to produce output $T_{t}$ :

$$
T_{t}=k_{t}^{\alpha} h_{t}^{1-\alpha}
$$

Moreover, we assume that the production in the non-tradable sector is based on an endowment which is fixed ${ }^{6}$ over time to $N$ :

$$
N_{t}=N
$$

\subsubsection{Non-linear equilibrium conditions}

The representative household maximizes lifetime utility (20) subject to the budget constraint in (21), and chooses the optimal path of $\left\{c_{n t}, c_{t}, h_{t}, i_{t}, y_{t}, k_{t+1}, d_{t+1}, \lambda_{t}\right\}_{t=0}^{\infty}$. Thus, the following system of nonlinear equations describe the optimal dynamics of the model variables $\left\{c_{n t}, c_{t}, h_{t}, i_{t}, y_{t}, k_{t+1}, d_{t+1}, \lambda_{t}, p_{t}, r_{t}\right\}_{t=0}^{\infty}$ :

$$
\begin{gathered}
\left(c_{n t}^{b} c_{t}^{1-b}-h_{t}^{\omega} / \omega\right)^{-\sigma} b c_{n t}^{b-1} c_{t}^{1-b}=\lambda_{t} \\
\left(c_{n t}^{b} c_{t}^{1-b}-h_{t}^{\omega} / \omega\right)^{-\sigma}(1-b) c_{n t}^{b} c_{t}^{-b}=\lambda_{t} p_{t} \\
\left(c_{n t}^{b} c_{t}^{1-b}-h_{t}^{\omega} / \omega\right)^{-\sigma} h_{t}^{\omega-1}=\lambda_{t} p_{t}(1-\alpha) k_{t}^{\alpha} h_{t}^{-\alpha} \\
\lambda_{t} p_{t}=\beta \lambda_{t+1} p_{t+1}\left[1+r\left(d_{t+1}\right)\right] \\
\lambda_{t} p_{t}\left[1+\phi\left(k_{t+1}-k_{t}\right)\right]=\beta \lambda_{t+1} p_{t+1}\left[1-\delta+\phi\left(k_{t+2}-k_{t+1}\right)+\alpha\left(\frac{k_{t+1}}{h_{t+1}}\right)^{\alpha-1}\right] \\
p_{t} d_{t+1}=p_{t}\left(1+r_{t}\left(d_{t+1}\right)\right) d_{t}+p_{t} c_{t}+c_{n, t}+p_{t} i_{t}-y_{t}+p_{t} \frac{\phi}{2}\left(k_{t+1}-k_{t}\right)^{2}
\end{gathered}
$$

of foreign currency in terms of domestic currency. Thus, an increase in the relative price (i.e. real exchange rate) captures a real depreciation of the domestic currency relative to the foreign currency.

${ }^{6}$ One can generalize this assumption by making assumptions about the nature of the technology, the type of the inputs used etc. This generalization would not affect the conclusions that we draw in this paper. 


$$
\begin{gathered}
y_{t}=N+p_{t} k_{t}^{\alpha} h_{t}^{1-\alpha} \\
k_{t+1}=(1-\delta) k_{t}+i_{t} \\
r\left(d_{t+1}\right)=r^{*}+\psi\left(\exp \left(\frac{d_{t+1}}{y_{t}}-\widetilde{d}\right)\right) \\
c_{n t}=N
\end{gathered}
$$

\section{Calibration}

In order to solve the system of difference equations that characterize the optimal decision of the small open economy in the two versions of the RBC model considered in the previous section, we have to assign values to the model parameters. In this section we describe the way we calibrate these parameters which we group in two categories: financial parameters such as the elasticity of country spread and other model parameters.

\subsection{The elasticity of country spread with respect to the debt to GDP ratio}

The elasticity of country spread with respect to the debt to GDP ratio of the small open economy, $\psi$, plays an important role in understanding the channels through which the small open economy adjusts externally. As the size of this parameter determines the size of the country spread for a given gap between the actual and steady state debt to GDP ratio, it has implications for the importance of the financial channel relative to the trade channel.

The small open economy real business cycle literature focusing on emerging economies has been traditionally calibrating this parameter to the value 0.001 . This calibration was first introduced by Mendoza (1991) that studied real business cycle fluctuations in the case of the Canadian economy. This calibration quantitatively implies a country spread which is close to zero. As we show in Table 1, a 0.1 increase in the debt to GDP ratio relative to the steady state induces only one basis point increase in the country spread. The cost of borrowing of the small open economy is about the same as the world interest rate, exogenous to the small open economy, under this calibration.Thus, we expect that none or only a tiny fraction of the overall external adjustment is through the financial channel. We label this 
case as the "No financial adjustment" case as outlined in the third column of Table 1.

Table 1. Calibration of the elasticity of country spread w.r.t. the debt to GDP ratio $(\psi)$

\begin{tabular}{|c|c|c|c|}
\hline $\begin{array}{c}\text { Value of } \\
\psi\end{array}$ & Source & $\begin{array}{c}\text { Type of adjustment } \\
\text { in the model }\end{array}$ & $\begin{array}{c}\text { Implied adjustment } \\
\text { in spread (bp) }\end{array}$ \\
\hline \hline 0.001 & Mendoza (1991) & No financial adjustment & 1 \\
\hline 0.07 & Rowland and Torres (2004) & Financial adjustment & 70 \\
\hline 1.3 & Schmitt-Grohe and Uribe (2016) & Financial adjustment & 1300 \\
\hline
\end{tabular}

The empirical literature which investigates the determinants of country spread (Cantor and Packer, 1996; Eichengreen and Mody, 1998; Hilscher; Rowland and Torres, 2004; Nosbusch et al, 2010) has concluded that it is misleading to assume that country spread is exogenous, by pointing out that there is not only a certain feedback relationship between the country spread and the world interest rate, but the country spread also reacts to movements in economic fundamentals such as the degree of the external indebtedness of the country. A series of reduced form papers have shown recently that in the case of emerging economies the elasticity of country spread with respect to fluctuations in the external debt position of these countries is much larger. For instance, Rowland and Torres (2004) estimate, by using panel data econometrics techniques, that an average increase of 0.1 in the debt to GDP ratio implies a 70 basis point increase on average in the JP Morgan EMBI Global spread in the case of a panel of sixteen emerging economies. Considering a larger set of emerging economies, a panel of thirty-one countries, Hilscher et al. (2010) also document a similar size of the elasticity of country spread: they estimate in a panel regression framework that a 0.1 increase in the debt to GDP ratio implies an increase of the country spread by about 50 basis points.

In addition to these reduced form findings, we also document in this paper that the elasticity of country spread with respect to the debt to GDP ratio is much higher than 0.001. By using Bayesian estimation techniques, we estimate a small open economy real business cycle model with endogenous country spread in the case of five Central and Eastern 
European countries ${ }^{7}$. Table 2 contains the point estimates of the $\psi$ parameter.

Table 2. Bayesian estimates of $\psi$ based on a prior distribution gamma

with expected value 0.15 and standard deviation 0.05

\begin{tabular}{|l|c|c|c|}
\hline \multicolumn{1}{|c|}{ Country } & $\begin{array}{c}\text { Posterior } \\
\text { mean }\end{array}$ & $\begin{array}{c}\text { Confidence } \\
\text { interval }\end{array}$ & $\begin{array}{c}\text { Implied adjustment } \\
\text { in spread (bp) }\end{array}$ \\
\hline \hline Bulgaria & 0.044 & {$[0.013,0.073]$} & 44 \\
\hline Czech Republic & 0.061 & {$[0.023,0.094]$} & 61 \\
\hline Hungary & 0.072 & {$[0.029,0.112]$} & 72 \\
\hline Poland & 0.077 & {$[0.031,0.124]$} & 77 \\
\hline Romania & 0.081 & {$[0.032,0.131]$} & 81 \\
\hline
\end{tabular}

Note: Confidence interval concerning the $90 \%$ probability region.

The posterior mean ranges between 0.04 and 0.08 , suggesting that the size of elasticity of country spread with respect to the debt to GDP ratio implied by the structure of the small open economy RBC model and observables on output, consumption, investment and net exports, is consistent with the reduced form findings. An increase in the debt to GDP ratio by 0.1 induces about 70 basis point increase in the spread on average across the five countries in the case for which we performed the estimation.

Thus, in line with the reduced form findings of the previous literature and the structural estimates documented in this paper, we consider a case in which we calibrate the $\psi$ parameter to 0.07 . As outlined in Table 1, we consider a third case in which we calibrate $\psi$ to 1.3 , a value that is documented by Schmitt-Grohe and Uribe (2016) in the case of Argentina. However, this large elasticity implies a 1300 basis point increase in the country spread for a 0.1 increase in the debt to GDP ratio.

\subsection{Other parameters of the model}

We calibrate the other parameters of the models by closely following the calibration used in the real business cycle literature on emerging economies as summarized in Table 3. We calibrate the capital share of income $(\alpha)$ to the long-run average of the compensation of labor input to value added ratio in emerging economies. The rate of depreciation of capital $(\delta)$ is calibrated to 0.1 .

The preference parameters are set as follows: the coefficient of relative risk aversion $(\sigma)$

\footnotetext{
${ }^{7}$ The model is similar in structure to the model outlined in this paper. Details on the model and the estimation are included in Section $\mathrm{C}$ of the Appendix.
} 
defining the curvature of the utility function is set to 2, while the exponent of labor in the utility function, $\omega$, is set to 1.455. These are in line with Schmitt-Grohe and Uribe (2003), Neumeyer and Perri (2005) and Garcia-Cicco et al. (2010).

Table 3. Calibration of the other model parameters

\begin{tabular}{|c|l|r|}
\hline Parameter & \multicolumn{1}{|c|}{ Comments } & Value \\
\hline$\alpha$ & Capital share of income & 0.32 \\
\hline$\delta$ & Capital depreciation & 0.1 \\
\hline$\sigma$ & Relative risk aversion & 2 \\
\hline$\omega$ & Labor in the utility function & 1.455 \\
\hline$r^{*}$ & Steady state level of gross foreign real interest rate & 0.01 \\
\hline$\widetilde{d}$ & Countries' long run external debt to GDP ratio & 0.744 \\
\hline$\phi$ & Capital adjustment cost parameter & 8 \\
\hline$b$ & Share of non-tradable sector & 0.7 \\
\hline$N$ & Endowment in the non-tradable sector & 70 \\
\hline
\end{tabular}

The steady state level of gross foreign real interest rate or risk free real interest rate $\left(\bar{r}^{*}\right)$ is calibrated to 0.01 which implies a discount factor $(\beta)$ equal to 0.99 . $\widetilde{d}$, the long run external debt to GDP ratio, is set to 0.744 in line with Schmitt-Grohe and Uribe (2003) who argue that this is consistent with the average of the net foreign asset to GDP ratio across emerging economies. Following the same paper, we calibrate the capital adjustment cost parameter $(\phi)$ to 8 . The rationale behind this large value is twofold. On the one hand, adjusting capital stock in emerging economies is costly given a series of capital market frictions that are not present in developed economies. On the other hand, setting this parameter to a lower value would imply that investment is too volatile relative to the data.

Finally, we assume that the non-tradable sector accounts for about $70 \%$ of the total output of the small open economy setting in this way parameter b to 0.7. Moreover, we assume that the endowment in the non-tradable sector is constant over time and we set it to 70. This is a simplifying assumption which does not have implications for the conclusions at which we arrive based on the simulation exercise in the next section. 


\section{The External Financial Adjustment of the Small Open Economy}

In this section we use the two small open economy real business cycle models outlined in Section 3 to study how the financial and trade channels operate in an explicit intertemporal model that pins down the equilibrium paths of real exchange rate and forecastable returns on the net international investment position of the small open economy. Moreover, by using the calibrations presented in the previous section, we simulate the non-linear model under the assumption of perfect foresight to study how the two financial channels interact with the trade channel and shed light on the mechanism through which these channels operate.

The findings of the simulation exercise are striking. First, we show that the financial channel plays a more important role relative to the trade channel in the external adjustment of the emerging countries when the country's external spread is more sensitive to fluctuations in the debt to GDP ratio relative to the steady state. This is mainly due to the positive financial externality present in the model implied mechanism, the importance of which increases with the debt elasticity of the spread. Second, we document that initial conditions matter for the type of the channel through the country undergoes the external adjustment. The results of the simulation exercise show that the larger the initial external debt position of the country relative to steady state is, the more important the financial channel is. Third, we show that the financial channel plays a more important role than the trade channel in the long run. Finally, we show that the global results are different from the local ones: the financial channel plays a smaller role in the log-linearized model. The following two sections present the details and demonstrate these findings. First, we take the small open economy RBC model augmented with endognous country spread and simulate it to study the importance of the real interest rate channel, as the only financial channel in this version of the model, relative to the trade channel. Then, we simulate the second version of the model that encompasses both the real interest rate and real exchange rate as financial channels.

\subsection{The Role of the Real Interest Rate Channel}

In order to study the relative importance of the trade and real interest rate channels in the small open economy's external adjustment process, we first perform simulations of the small open economy real business cycle model augmented by endogenous country spread. Thus, in this version of the model the real interest rate is the only channel of financial adjustment. We

calibrate the system of non-linear equations in (11) - (18). As we assume perfect foresight, this exercise is nothing else than a deterministic simulation of the non-linear equilibrium 
conditions by using numerical methods. Thus, we can study the global dynamics of the simulated adjustment instead of the local one which was the case if we log-linearized the system. We simulate the adjustment of the model economy back to the steady state from an initial state in which all the model variables, except the capital stock and the external debt position, are at their steady state value. We assume that initially the capital stock is by $10 \%$ below its steady state, while the external debt position is by $10 \%$ above its steady state. We perform the simulation in two cases. First we assume that the elasticity of country spread, $\psi$, is low by calibrating it to 0.001 . Then, we keep all the parameter values the same but we increase the value of $\psi$ to 0.07 . The results of the simulation under the two calibrations of $\psi$ are summarized in Figure 1. These simulation results suggest a series of interesting findings.

First, the financial channel seems to play a much more important role than the trade channel when the country spread is more sensitive to fluctuations in the debt to GDP ratio relative to the steady state. By comparing the adjustment path of the external debt, the country spread, the current account and the trade balance, we can easily notice that the external adjustment takes place through a combination of the trade and real interest rate channels. However, starting from period thirty the type of the adjustment becomes very different across the two economies. In particular, the external adjustment of the economy that has low elasticity of the spread (i.e. $\psi$ calibrated to 0.001) is only through adjustment in current account starting from period thirty. As the cost of borrowing is not sensitive to the increase in external debt, the country over-borrows in order to build up capital stock and all the external adjustment is through the trade channel. On the other hand, in the economy with the larger elasticity of the spread most of the adjustment in the initial periods and all of the adjustment on the long run is through the financial channel, i.e. the real interest rate channel. As the country spread is sensitive to fluctuations in the external debt in this economy, the country will pay down debt and build up capital stock by saving and running trade surplus in the initial periods of the adjustment. But in period thirty, the economy reaches the level of external debt and capital stock that is consistent with the steady state level of trade balance and current account. Thus, starting from this period all the adjustment is through the real interest rate channel. This difference in the importance of the financial channel across economies with different values of $\psi$ becomes even more striking when we calibrate this parameter to 1.3. Appendix E.1. summarizes the simulation results which suggest that essentially all the external adjustment is through the financial channel when the country spread is extremely sensitive to fluctuations in the external debt position 
relative to steady state.

Figure 1. Results of the simulation of the small open economy RBC model with endogenous country spread
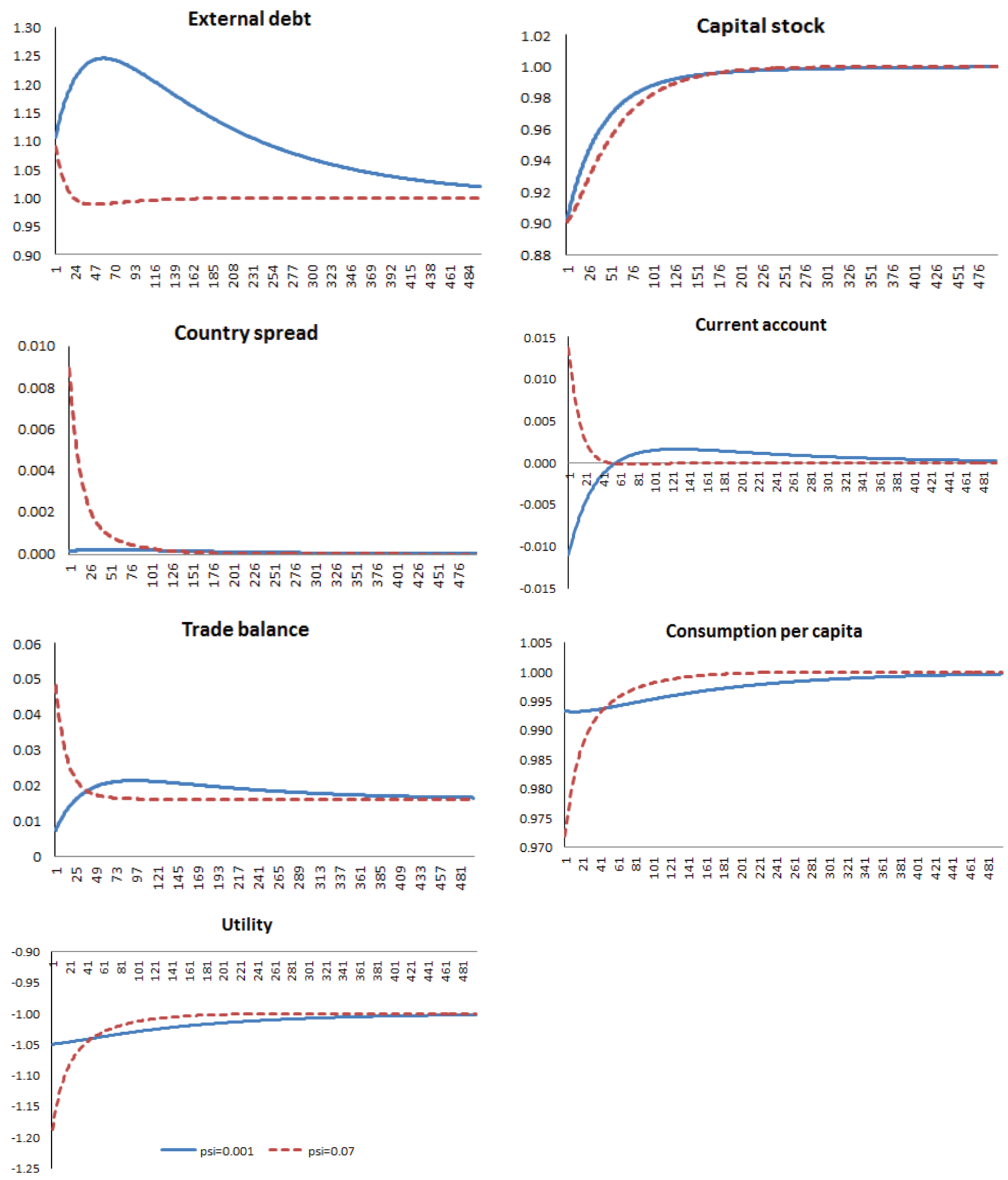

Note: Initial external debt above and capital below the steady state by $10 \%$.

The rest of the model variables are initially at steady state. 
Second, by examining the adjustment path of consumption per capita and utility, one can notice that there seems to be a gain from the financial adjustment. This is because the financial adjustment rewards countries for paying down debt. This is rationalized in the model by the positive financial externality created by the endogenous country spread. Since the spread depends on the deviation of the external debt to GDP ratio from its steady state, building up capital stock and financing domestic consumption by building up new external debt increases the cost of borrowing tomorrow and creates debt spiral over time. Moreover, this increase in the cost of borrowing tomorrow is larger the larger the debt elasticity of the spread. The small open economy internalizes the consequences of building up more debt today as it makes per-period decisions by an optimal consumption-saving decision over time. Thus, it will start the external adjustment by saving and paying down debt in the initial periods that generates a positive financial externality over time, as the cost of external borrowing falls over time. The more external debt is payed down, the larger the fall in the cost of borrowing over time such that the spread adjusts back to a level at which the small open economy can restart borrowing from the international markets.

The presence of the positive financial externality in the model rationalizes the finding that the importance of the financial channel increases with the size of the debt elasticity of the spread. Moreover, by the presence of this financial externality, the financial channel has also non-trivial implications for welfare. Table 4 contains the sum of discounted simulated utilities under different calibrations of the debt elasticity of country spread ${ }^{8}$, and under the assumption that the initial debt is above its steady state debt by $10 \%$, while the initial capital stock is below its steady state by $10 \%$.

Table 4. The sum of discounted utilities and the elasticity of country spread

\begin{tabular}{|l|l|l|l|}
\hline$\psi$ & 0.001 & 0.7 & 1.3 \\
\hline Life-time utility $\left(\mathrm{U}_{0}\right)$ & 103.02 & 104.05 & 123.4 \\
\hline
\end{tabular}

It shows that the larger $\psi$ is the larger the discounted sum of lifetime utility implied by the model. This suggests that there is always a gain from financial adjustment because it rewards countries over time for paying down debt.

However, the financial externality and, thus, the financial channel plays an important role in the external adjustment of the small open economy if the country starts the adjustment from an initial external debt position that is above the steady state. In order to illustrate this, we do additional simulation exercises in which we fix the initial external debt position

\footnotetext{
${ }^{8}$ To compute this, we simulate the consumption and hours worked under different parametrizations of $\psi$ and compute the life-time utility as $\sum_{t=0}^{\infty} \beta U\left(c_{t}, h_{t}\right)$ with $\beta$ equal to 0.99 , the discount factor value implied by the $r^{*}$ calibrated to 0.01 .
} 
at a level below the steady state by 0.1. Table 5 contains the sum of discounted simulated utilities under different calibration of the debt elasticity of country spread and different assumptions on the initial value of the external debt position and capital stock ${ }^{9}$. Essentially, the difference in the level of life-time utilities across the economies with different $\psi$ is given by the positive financial externality that is quantitatively important when the intial external debt is above its steady state. As Table 5 illustrates, the financial channel matters for the utility ranking only when the country is a net debtor on the international financial markets. When the initial debt is below the steady state (i.e. the initial external debt of the country is less than the steady state value), then the discounted lifetime utility is at the same level across the economies with and without IFA.

Table 5. The sum of discounted utilities and the elasticity of country spread

\begin{tabular}{|l|l|l|}
\hline$\psi$ & 0.001 & 0.07 \\
\hline Initial capital and debt below steady state by 0.1 & 37.6 & 37.4 \\
\hline Initial capital and debt above steady state by 0.1 & 37.7 & 38.1 \\
\hline Initial capital above and debt below steady state by 0.1 & 36.5 & 36.1 \\
\hline Initial capital below and debt above steady state by 0.1 & 38.9 & 39.4 \\
\hline
\end{tabular}

Finally, Figure 1 suggests that the financial channel plays a more important role in the external adjustment on the long run: as the country pays down external debt in the initial periods, it starts to enjoy the benefits of the financial externality on the long run and adjusts almost exclusively through the real interest rate channel. Figure 1 also suggests very different global results from the local ones which studies the patterns of financial adjustment in the neighborhood of the steady state. The first striking finding with respect to this is that the financial channel plays a small role in the log-linearized model. The second is that the interesting initial non-linearity in the adjustment is ignored in the log-linearized model. By looking at the adjustment path of the external debt position in the neighborhood of the steady state (i.e. around period four hundred) one would ignore not only the initial overand under-shooting in the external debt position in the initial periods of the adjustment, but also the presence of real interest rate as adjustment channel. This is mainly because the country spread is close to zero for these values of the external debt.

\footnotetext{
${ }^{9}$ To compute this, we simulate the consumption and hours worked under different parametrizations of $\psi$ and compute the life-time utility as $\sum_{t=0}^{\infty} \beta U\left(c_{t}, h_{t}\right)$ with $\beta$ equal to 0.99 , the discount factor value implied by the $r^{*}$ calibrated to 0.01 .
} 


\subsection{The Relative Importance of the Real Exchange and Interest Rate Channels}

In order to study the relative importance of the trade, real interest rate and real exchange rate channels in the external adjustment process of the emerging economies, we first perform simulations of the small open economy RBC model augmented with endogenous spread, tradable and non-tradable sectors. Thus, in this version of the model the real interest rate and the real exchange are the channels of financial adjustment. We calibrate the system of nonlinear equations in (25) - (33). Similarly to the previous simulation, under the assumption of perfect foresight, we solve the non-linear equilibrium conditions by using numerical methods. Then, we simulate the model by assuming that the initial capital stock is by $10 \%$ below its steady state, while the external debt position is by $10 \%$ above its steady state and the elasticity of country spread, $\psi$, can take two values: 0.001 and 0.07 .

The results of the simulation under the two calibration of $\psi$ are summarized in Figure 2. These simulation results suggest that the findings documented in the previous section based on the simulation of the model with only real interest rate as financial channel are robust to the introduction of real exchange rate as an additional source of international financial adjustment. Thus, the financial channel seems to be more important on the long run, and in particular when the country spread is more sensitive to fluctuations in the debt to GDP ratio. The real exchange rate, defined as the relative price of tradables adjusts over time back to steady state through a real appreciation. However, there is essentially no significant difference in the adjustment path across the two economies except for the first few periods. All these suggest that the main source of external adjustment is the real interest rate channel 
in the emerging economies that are characterized by debt elastic country spread.

Figure 2. Results of the simulation of the small open economy RBC model with endogenous country spread, tradable and non-tradable sectors
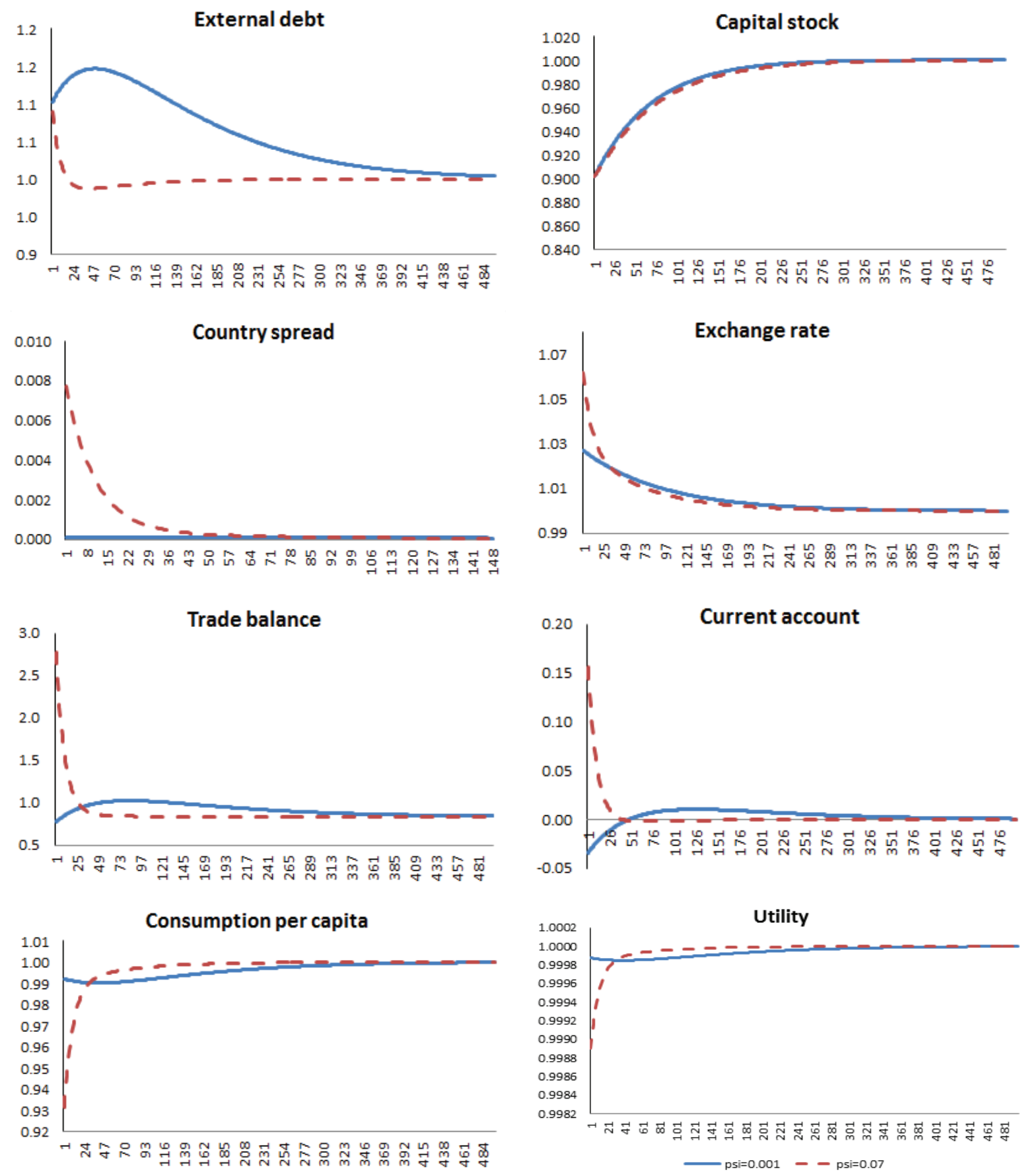

Note: Initial external debt above and capital below the steady state by $10 \%$.

The rest of the model variables are initially at steady state. 
The importance of the financial channel increases with the size of the debt elasticity of the spread also when real exchange rate as IFA channel is present in the model in addition to the country spread (i.e., the only channel of adjustment in the baseline verison of the model considered in the previous section). Table 6 contains the sum of discounted simulated utilities under different calibrations of the debt elasticity of country spread ${ }^{10}$, and under the assumption that the initial debt is above its steady state debt by $10 \%$, while the initial capital stock is below its steady state by $10 \%$.

Table 6. The sum of discounted utilities and the elasticity of country spread

\begin{tabular}{|l|l|l|}
\hline$\psi$ & 0.001 & 0.7 \\
\hline Life-time utility $\left(\mathrm{U}_{0}\right)$ & 96.12 & 97.11 \\
\hline
\end{tabular}

The two columns of Table 6 show that the larger $\psi$ is the larger the discounted sum of lifetime utility implied by the model. This suggests that there is always a gain from financial adjustment because it rewards countries over time for paying down debt.

\section{Conclusions}

In this paper we have calibrated and demonstrated the importance of IFA in a standard open economy growth model (Schmitt-Grohe and Uribe (2003)) with a well-defined steady level of foreign liabilities. In this model there is a country specific credit spread which varies as a function of the ratio of foreign liabilities to GDP. We studied a perfect foreign version of the model so that we could characterize the global dynamic adjustment in net foreign assets, the endogenous cost of debt service, and the path of the real exchange rate. This is important, because in this model, in a neighborhood of the steady state, IFA is not very important.

In our baseline simulation in which we calibrate the elasticity of the country credit spread to the debt to GDP ratio based on plausible empirical estimates from the literature as well as our own estimates, we find that allowing for an IFA channel results in a very rapid converge of the current account to its steady state (relative to the no IFA case) so that most of the time that the country is adjusting, all the adjustment is via forecastable changes in the costs of servicing debt and in the appreciation real exchange rate and none of the adjustment is in the current account. By contrast, in the no IFA case, current account adjustment by construction does all the work and current account adjustment calibrated to be much slower.

Finally we show that IFA adjustment via the real exchange rate can be important even if

\footnotetext{
${ }^{10}$ To compute this, we simulate the consumption and hours worked under different parametrizations of $\psi$ and compute the life-time utility as $\sum_{t=0}^{\infty} \beta U\left(c_{t}, h_{t}\right)$ with $\beta$ equal to 0.99 , the discount factor value implied by the $r^{*}$ calibrated to 0.01 .
} 
forecastable changes in the cost of debt service are not. We discussed above, in this textbook model there is a negative externality to foreign borrowing in that no borrower internalizes that the credit spread faced by borrowers in the country are a function of aggregate debt. We were able quantify that not only is IFA important in this model, lifetime utility in the model with IFA is higher than in the model without even though - really because - the cost of debt service is higher period by period until convergence is achieved.

\section{References}

Aguiar, M. and Gopinath, G. (2007a), "Emerging Market Business Cycles: The Cycle Is the Trend", Journal of Political Economy, University of Chicago Press, vol. 115, pages 69-102.

Aguiar, M. and Gopinath, G. (2007b), "The Role of Interest Rates and Productivity Shocks in Emerging Market Fluctuations", Working Papers Central Bank of Chile 445, Central Bank of Chile.

An, S. and Schorfheide, F. (2005), "Bayesian Analysis of DSGE Models", CEPR Discussion Papers 5207, C.E.P.R. Discussion Papers.

An, S. and Schorfheide, F. (2007), "Bayesian Analysis of DSGE Models", Econometric Reviews, Taylor and Francis Journals, vol. 26(2-4), pages 113-172.

Arellano, C. and Mendoza, E. G. (2002), "Credit Frictions and 'Sudden Stops' in Small Open Economies: An Equilibrium Business Cycle Framework for Emerging Markets Crises", NBER Working Papers 8880, National Bureau of Economic Research, Inc.

Arellano, C. and Ramanarayanan, A. (2006) "Default and the Term Structure in Sovereign Bonds", 2006 Meeting Papers 299, Society for Economic Dynamics.

Cantor, R., Packer, F. (1996), "Determinants and impact of sovereign credit ratings", Economic Policy Review, vol. 2(2), pages 37-53, Federal Reserve Bank of New York.

Chang, R. and Fernández, A. (2009), "On the Sources of Aggregate Fluctuations in Emerging Economies", Working Paper, Department of Economics Rutgers University.

Chang, R. and Fernández, A. (2010), "On the Sources of Aggregate Fluctuations in Emerging Economies", NBER Working Paper 15938, National Bureau of Economic Research, Inc.

Cummins, J. G., Hassett, K. A. and Oliner, S. D. (2006), "Investment Behavior, Observable Expectations, and Internal Funds", American Economic Review, American Economic Association, vol. 96(3), pages 796-810. 
Eichengreen, B. and Mody, A. (1998), "What Explains Changing Spreads on EmergingMarket Debt: Fundamentals or Market Sentiment?", NBER Working Papers 6408, National Bureau of Economic Research, Inc.

Ermolaev et al. (2008), "Estimating GPM with Dynare", mimeo.

Garcia-Cicco, J., Pancrazi, R. and Uribe, M. (2006), "Real Business Cycles in Emerging Countries?", NBER Working Paper 12629, National Bureau of Economic Research, Inc.

Garcia-Cicco, J., Pancrazi, R. and Uribe, M. (2010), "Real Business Cycles in Emerging Countries?", American Economic Review, forthcoming.

Geweke, J. (1998) "Using simulation methods for Bayesian econometric models: inference, development, and communication", Staff Report 249, Federal Reserve Bank of Minneapolis.

Gourinchas, P. O. and Rey, H. (2007), "International Financial Adjustment", Journal of Political Economy, vol. 115(4).

Greenwood, J, Hercowitz, Z. and Huffman, G. W. (1988), "Investment, Capacity Utilization, and the Real Business Cycle", American Economic Review, vol.78(3), pages 402-417.

Hilscher, J. and Nosbusch, Y. (2010), "Determinants of Sovereign Risk: Macroeconomic Fundamentals and the Pricing of Sovereign Debt", Review of Finance, Oxford University Press for European Finance Association, vol. 14(2), pages 235-262.

Lubik, T. And Schorfheide, F. (2005), "A Bayesian Look at New Open Economy Macroeconomics", Economics Working Paper Archive 521, The Johns Hopkins University, Department of Economics.

Mendoza, E.G. (1991), "Real Business Cycles in a Small Open Economy," American Economic Review, American Economic Association, vol. 81(4), pages 797-818.

Neumeyer P. A. and Perri, F. (1999), "Business Cycles in Emerging Economies: the role of interest rates", Department of Economics Working Papers 014, Universidad Torcuato Di Tella.

Neumeyer P. A. and Perri, F. (2001), "Business Cycles in Emerging Economies:The Role of Interest Rates", Working Papers 01-12, New York University, Leonard N. Stern School of Business, Department of Economics. 
Neumeyer, P. A. and Perri, F. (2005), "Business cycles in emerging economies: The role of interest rates", Journal of Monetary Economics, 52, pp. 345-380.

Rowland, P. and Torres, J. L. (2006), "Determinants of Spread and Creditworthiness for Emerging Market Sovereign Debt: A Panel Data Study", Banco de la República Working Paper.

Schmitt-Grohe, S. and Uribe, M. (2003), "Closing small open economy models", Journal of International Economics, Elsevier, vol. 61(1), pages 163-185.

Schorfheide, F. (2005), "Learning and Monetary Policy Shifts", Review of Economic Dynamics, Elsevier for the Society for Economic Dynamics, vol. 8(2), pages 392-419.

Smets, F. and Wouters, R. (2003), "An Estimated Dynamic Stochastic General Equilibrium Model of the Eurozone", Journal of the European Economic Association, MIT Press, vol. $1(5)$, pages $1123-1175$.

Smets, F. and Wouters, R. (2007), "Shocks and Frictions in US Business Cycles: A Bayesian DSGE Approach", CEPR Discussion Papers 6112, C.E.P.R. Discussion Papers.

Uribe, M. and Yue, V. Z. (2003), "Country Spreads and Emerging Countries: Who Drives Whom?", NBER Working Papers 10018, National Bureau of Economic Research, Inc.

Uribe, M. and Yue, V. Z. (2006), "Country spreads and emerging countries: Who drives whom?", Journal of International Economics, Elsevier, vol. 69(1), pages 6-36. 


\section{Appendix}

\section{A. Derivation of the BoP accounting identity with zero gross international asset position}

We aim to derive the log-linearized balance of payment accounting identity in the special case when the gross international asset position of the country is zero in any time period, i.e. $\mathrm{A}_{t+1}=A_{t}=0$.

The BoP accounting identity in levels is:

$$
\frac{A_{t+1}-L_{t+1}}{A_{t}-L_{t}}=R_{t+1}\left(1+\frac{X_{t}-M_{t}}{A_{t}-L_{t}}\right)
$$

where $A_{t}$ is the gross international asset position, $L_{t}$ is the gross international liability position, $R_{t}$ is the real interest rate, $X_{t}$ is total exports and $M_{t}$ is total imports.

The assumption $\mathrm{A}_{t+1}=A_{t}=0$ implies that $\mathrm{A} .1$ can be written as:

$$
\frac{L_{t+1}}{L_{t}}=R_{t+1}\left(1-\frac{X_{t}-M_{t}}{L_{t}}\right)
$$

While the steady state value of the gross asset position is zero, i.e. $A=0$.

In the following, we want to show that the log-linearized version of the identity in A.2 is:

$$
l_{t}=n x_{t}-\rho n x_{t}+\rho l_{t+1}-\rho r_{t+1}
$$

where $l_{t}$ is the log-deviation of the gross liability position from its steady state, $n x_{t}$ is the log-deviation of net exports, defined as $X_{t}-M_{t}$ from its steady state, $r_{t+1}$ is the log deviation of the real interest rate from its steady state, $\rho \equiv 1-\frac{X-M}{L}$ with $X, M$ and $L$ being the steady state values of exports, imports and gross liability position.

By iterating forward on A.3 we get the intertemporal balance of payment identity that pins down the current level of gross liability as the function of the discounted sum of future real service of the external debt and the discounted sum of future changes in net exports:

$$
l_{t}=-\sum_{j=1}^{\infty} \rho^{j} r_{t+j}+n x_{t}+\sum_{j=1}^{\infty} \rho^{j} \Delta n x_{t+j}
$$

\section{Proof:}


First, we want to log-linearize A.2 which we do in three steps.

Step 1: (A.2) in steady state, denoted with the same letters but with the time index omitted, becomes:

$$
1=R\left(1-\frac{X-M}{L}\right)
$$

After some algebraic manipulation we get:

$$
\frac{1}{R}=1-\frac{X-M}{L}
$$

Denote $\frac{1}{R} \equiv \rho$. Then, we can rewrite (A.6) as:

$$
\rho \equiv 1-\frac{X-M}{L}
$$

Step 2: Take the log of (A.2):

$$
\log \left(L_{t+1}\right)-\log \left(L_{t}\right)=\log \left(R_{t+1}\right)+\log \left(1-\frac{X_{t}-M_{t}}{L_{t}}\right)
$$

Step 3: Take first-order Taylor series expansion of the expression in (A.8) around the $\log$ steady-state.

First, let's focus on the left-hand side of the expression and write its first-order Taylor series expansion as:

$$
\begin{aligned}
\log \left(L_{t+1}\right)-\log \left(L_{t}\right) & =\log \left(e^{\log \left(L_{t+1}\right)}\right)-\log \left(e^{\log \left(L_{t}\right)}\right) \simeq \\
& \simeq \log (L)-\log (L)+\frac{1}{e^{\log (L)}} e^{\log (L)}\left(\log \left(L_{t+1}\right)-\log (L)\right)- \\
& -\frac{1}{e^{\log (L)}} e^{\log (L)}\left(\log \left(L_{t}\right)-\log (L)\right) \\
& =\left(\log \left(L_{t+1}\right)-\log (L)\right)-\left(\log \left(L_{t}\right)-\log (L)\right)
\end{aligned}
$$

Denote the deviation of the variable from the $\log$ steady state as $x_{t}=\log \left(X_{t}\right)-\log (X)$. Then, (A.9) can be written as:

$$
\log \left(L_{t+1}\right)-\log \left(L_{t}\right) \simeq l_{t+1}-l_{t}
$$

Second, we take the first-order Taylor series expansion of the right-hand side of (A.8) around the steady state: 


$$
\begin{aligned}
\log \left(R_{t+1}\right)+\log \left(1-\frac{X_{t}-M_{t}}{L_{t}}\right) & =\log \left(e^{\log \left(R_{t+1}\right)}\right)+\log \left(1-\frac{e^{\log \left(N X_{t}\right)}}{e^{\log \left(L_{t}\right)}}\right) \simeq \\
& \simeq \frac{1}{e^{\log (R)} e^{\log (R)}\left(\log \left(R_{t+1}\right)-\log (R)\right)+} \\
& +\frac{1}{1-\frac{e^{\log (N X)}}{e^{\log (L)}}}\left(-\frac{e^{\log (N X)}}{e^{\log (L)}}\right)\left(\log \left(N X_{t}\right)-\log (N X)\right)+ \\
& +\frac{1}{1-\frac{e^{\log (N X)}}{e^{\log (L)}}}\left(-\frac{-e^{\log (N X)}\left(e^{\log (L)}\right)}{\left(e^{\log (L)}\right)^{2}}\right)\left(\log \left(L_{t}\right)-\log (L)\right) \\
& =\left(\log \left(R_{t+1}\right)-\log (R)\right)+ \\
& +\frac{N X}{N X-L}\left(\log \left(N X_{t}\right)-\log (N X)\right)+ \\
& -\frac{N X}{N X-L}\left(\log \left(L_{t}\right)-\log (L)\right) \\
& =\left(\log \left(R_{t+1}\right)-\log (R)\right) \\
& +\frac{N X}{N X-L}\left[\left(\log \left(N X_{t}\right)-\log (N X)\right)-\left(\log \left(L_{t}\right)-\log (L)\right)\right]
\end{aligned}
$$

By using the notation in the case of log deviations, (A.10) becomes:

$$
\log \left(R_{t+1}\right)+\log \left(1-\frac{X_{t}-M_{t}}{L_{t}}\right) \simeq r_{t+1}+\frac{N X}{N X-L}\left[n x_{t}-l_{t}\right]
$$

By using expression (A.7) derived in the steady state, we can rewrite $\frac{N X}{N X-L}$ as:

$$
\begin{aligned}
\frac{N X}{N X-L} & =\frac{X-M}{X-M-L}=\frac{X-M-L+L}{X-M-L}=1+\frac{L}{X-M-L} \\
& =1+\frac{1}{\frac{X-M}{L}-1}=1-\frac{1}{1-\frac{X-M}{L}}= \\
& =1-\frac{1}{\rho}
\end{aligned}
$$

Thus, the log-linearized version of equation (A.2) is:

$$
l_{t+1}-l_{t}=r_{t+1}+\left(1-\frac{1}{\rho}\right)\left[n x_{t}-l_{t}\right]
$$


By rearranging A.12 we get:

$$
l_{t}=n x_{t}-\rho n x_{t}+\rho l_{t+1}-\rho r_{t+1}
$$

One can easily notice that the expression in A.13 is exactly the expression in A.3 that we wanted to show.

Next, we want to show that A.4 holds in this framework. By iterating forward on (A.13) we get:

$$
l_{t+1}=n x_{t+1}-\rho n x_{t+1}+\rho l_{t+2}-\rho r_{t+2}
$$

Use (A.14) and plug it into (A.13):

$$
\begin{aligned}
l_{t} & =n x_{t}-\rho n x_{t}+\rho\left(n x_{t+1}-\rho n x_{t+1}+\rho l_{t+2}-\rho r_{t+2}\right)-\rho r_{t+2} \\
& =n x_{t}+\rho\left(n x_{t+1}-n x_{t}\right)-\rho^{2} n x_{t+1}+\rho^{2} l_{t+2}-\rho r_{t+1}-\rho^{2} r_{t+2} \\
& =n x_{t}+\rho \Delta n x_{t+1}-\sum_{j=1}^{2} \rho^{j} r_{t+j}+\rho^{2} l_{t+2}-\rho^{2} n x_{t+1}
\end{aligned}
$$

Similarly, by iterating n-steps ahead and plugging the iterated expression back into (A.15) we get:

$$
l_{t}-n x_{t}=\sum_{j=1}^{n} \rho^{j} \Delta n x_{t+j}-\sum_{j=1}^{n} \rho^{j} r_{t+j}+\rho^{n} l_{t+n+1}-\rho^{n} n x_{t+n}
$$

By using the transversality condition on the gross liability position:

$$
\lim _{n \rightarrow \infty} E\left[\rho^{n} l_{t+n+1}\right]=0
$$

and taking expression (A.16) in expectation conditional on information available at time t, we get the expression:

$$
n x_{t}-l_{t}=\sum_{j=1}^{\infty} \rho^{j}\left(r_{t+j}-\Delta n x_{t+j}\right)
$$

By re-arranging terms, (A.18) can be written as:

$$
l_{t}=-\sum_{j=1}^{\infty} \rho^{j} r_{t+j}+n x_{t}+\sum_{j=1}^{\infty} \rho^{j} \Delta n x_{t+j}
$$

But this is exactly the identity that we have in (A.4). Thus, we just proved that the current gross liability position can be written as the expression in A.4.

\section{B. Estimation Appendix}

The bayesian estimates of the model parameters included in Table 2 of Section X are obtained by structurally estimating a full scale small open economy RBC model by using 
Bayesian techniques. This model is consistent with the small open economy model with endogenous country spread considered in Section 3. Here we augment this model with a working capital constraint. This appendix is organized as follows. First, we outline the model. Then we present the estimation strategy we use to parameterize the model.

\section{B.1. Model specification}

\section{B.1.1 Households' behavior}

The representative household chooses the sequence of values for $\left\{C_{t}, h_{t}, I_{t}, K_{t+1}, D_{t+1},\right\}_{t=0}^{\infty}$ in order to maximize the expected discounted sum of lifetime utility derived from the consumption of goods and leisure:

$$
\max _{\left\{C_{t}, h_{t}, K_{t+1}, D_{t+1}\right\}_{t=0}^{\infty}} E_{0} \sum_{t=0}^{\infty} \beta^{t} U\left(C_{t}, h_{t}, \Gamma_{t-1}\right)
$$

where $C_{t}$ is time $t$ consumption, $h_{t}$ labor supplied by the household at time $t, \beta$ is the discount factor, $\Gamma_{t-1}$ allows for balanced growth path in utility ${ }^{11}, \mathrm{U}()$ is twice differentiable concave utility function, increasing in its first argument and decreasing in its second argument.

The household acquires income by supplying labor, $h_{t}$ to the firms and getting the wage, $w_{t}$ in exchange, by renting capital, $K_{t}$ to the firms at the rental rate of capital $u_{t}$, and by borrowing from, $D_{t+1}>0$ or by investing, $D_{t+1}<0$ in one period noncontingent bonds on the international financial market. Thus, one unit of foreign asset or debt costs $q_{t}$ in units of consumption goods. The household uses this income to purchase consumption goods, $C_{t}$, to invest in investment goods, $I_{t}$ and to pay back previous loans, $D_{t}>0$, contracted from or to sell international bonds, $D_{t}<0$, purchased from these markets. In this way she accumulates two types of capital stock which she owns entirely: physical capital, $K_{t}$ and internationally traded noncontingent bond, $D_{t}$. Thus, the household's per period budget constraint is:

$$
w_{t} h_{t}+u_{t} K_{t}+q_{t} D_{t+1}=D_{t}+C_{t}+I_{t}
$$

where the left-hand side of the identity characterizes the structure of the per period income, while the right-hand side represent the per period expenditures.

Changing the capital stock is costly and in each period $t$ it is realized according to a capital accumulation rule which states that the per period capital stock is nothing else than the sum of the existing capital stock net of depreciation, plus current investments minus the adjustment cost, $\Phi\left(K_{t+1}, K_{t}\right)$, paid for each unit of capital accumulated:

\footnotetext{
${ }^{11}$ More details about the way balanced growth path is defined you can find in the next subsection.
} 


$$
K_{t+1}=(1-\delta) K_{t}+I_{t}-\Phi\left(K_{t+1}, K_{t}\right) K_{t}
$$

This modeling technique is frequently used in the RBC literature because it improves the

performances of the model to generate moderate investment volatility and increases the persistence of investment. By assumption, $\Phi()$ is a strictly increasing, concave function.

\section{B.1.2. Firms' behavior}

The representative firm behaves in a perfectly competitive way, hires labor, $h_{t}$ and rents capital, $k_{t}$ in order to produce consumption goods, $Y_{t}$ based on a neoclassical production technology, $F()$ :

$$
Y_{t}=a_{t} F\left(K_{t}, \Gamma_{t} h_{t}\right)
$$

where $a_{t}$ models transitory technology improvement defined as an exogenous autoregressive stationary, $\left|\rho_{a}\right|<1$, process of order one:

$$
\log a_{t}=\rho_{a} \log a_{t-1}+\epsilon_{t}^{a}
$$

which captures shocks to total factor productivity as one source of uncertainty through $\epsilon_{t}^{a}$, i.i.d. process with mean zero and standard deviation $\sigma_{a} . \Gamma_{t}$ models permanent technology improvements as a labor augmenting productivity growth. As Aguiar and Gopinath (2007a) showed, assuming stochastic trend improvement, the neoclassical growth model does better job in replicating emerging market business cycle stylized facts like the countercyclical nature of trade balance to output ratio or higher volatility of consumption than output. The main intuition is related to the fact that as a result of a positive permanent productivity shock, labor productivity increases permanently. This generates a larger increase in permanent income and consumption than in current income which is financed by issuing external debt. In line with Aguiar and Gopinath (2007a), we assume that permanent technology shocks act through an exogenous and mean reverting stationary process:

$$
\begin{aligned}
\Gamma_{t} & =g_{t} \Gamma_{t-1} \\
\log \left(g_{t} / \mu\right) & =\rho_{g} \log \left(g_{t-1} / \mu\right)+\epsilon_{t}^{g}
\end{aligned}
$$

where $\left|\rho_{g}\right|<1, \epsilon_{t}^{g}$ is an i.i.d. process with mean zero and standard deviation $\sigma_{g}$, and it models shocks to labor productivity which are incorporated into $\Gamma_{t}$ through $g_{t}$, resulting in trend growth improvements. $\mu$ represents long-run labor productivity growth. 
The representative firm has the primary objective to maximize the total discounted sum of all future profits, $\Pi_{t}$, subject to a working capital constraint:

$$
\max _{\left\{a_{t}, h_{t}, k_{t}\right\}_{t+0}^{\infty}} E_{0} \sum_{t=0}^{\infty} \beta^{t} \Pi_{t}=E_{0} \sum_{t=0}^{\infty} \beta^{t}\left\{a_{t} F\left(K_{t}, \Gamma_{t} h_{t}\right)-w_{t} h_{t}\left[1+\theta\left(R_{t-1}-1\right)\right]-u_{t} K_{t}\right\}
$$

In other words, the working capital constraint induces an additional friction into the model since the representative firm must borrow at $R_{t-1}$ rate of interest from the representative household in each period in order to be able to finance $\theta$ fraction of the wage bill at the beginning of each period, in advance of the realization of the income. Neumeyer and Perri (2005) and Uribe and Yue (2006) argue that this financial friction creates a linkage between interest rate movements and real economic activity, which improves the ability of the baseline RBC model to generate strong countercyclical trade balance through the following mechanism: falling interest rate, on the one hand, reduces the cost of labor allowing firms to hire more labor and consequently to produce more output. On the other hand, the lower the cost of borrowing boosts aggregate demand which generates deterioration in trade balance. Thus output and trade balance move in the opposite direction when the cost of financing changes through borrowing.

\section{B.2. Closing the Model}

\section{B.2.1 The cost of borrowing}

In order to solve the model a few more assumptions are needed concerning the dynamics of domestic and world interest rates, country spread, the price of the foreign debt, and the functional forms of the utility, production and capital adjustment cost function.

We assume that the domestic interest rate at which households lend to firms is defined as the product of gross country spread, $S_{t}$, and gross foreign interest rate, $R_{t}^{*}$ :

$$
R_{t}=S_{t} R_{t}^{*}
$$

The dynamics of world interest rate is described by a mean reverting stationary, $\left|\rho_{r^{*}}\right|<$ 1, first order autoregressive process:

$$
\log \left(R_{t}^{*} / \bar{R}^{*}\right)=\rho_{r^{*}} \log \left(R_{t-1}^{*} / \bar{R}^{*}\right)+\epsilon_{t}^{r^{*}}
$$

where $\epsilon_{t}^{r^{*}}$ is an i.i.d. process with zero mean and standard deviation $\sigma_{r *}$. 
The country spread is not only the function of the permanent and transitory technology shocks, but also it depends on the household's external debt position fed into the cost of borrowing through an interest rate premium, $\Psi()$ :

$$
\log \left(S_{t} / \bar{S}\right)=-\eta\left[\log a_{t+1}+\log \left(g_{t+1}^{\alpha} / \mu^{\alpha}\right)\right]+\Psi\left(D_{t+1} / \Gamma_{t}\right)
$$

where $\Psi()$, is defined as an increasing and convex function of the external debt position of domestic household:

$$
\Psi\left(D_{t+1} / \Gamma_{t}\right)=\psi\left[\exp \left(\frac{D_{t+1}}{\Gamma_{t}}-\bar{d}\right)-1\right]
$$

In this way, the price of the external debt is given by:

$$
q_{t}=\frac{1}{R_{t}}
$$

\section{B.2.2. Functional forms}

Household's preferences are modeled according to Greenwood et al. (1988) (GHH) preferences $^{12}$ since many papers show that they improve the performances of international RBC models in replicating business cycle stylized facts:

$$
U\left(C_{t}, h_{t}, \Gamma_{t-1}\right)=\frac{\left(C_{t}-\tau \Gamma_{t-1} h_{t}^{\omega}\right)^{1-\sigma}}{1-\sigma}, \omega>1, \tau>0
$$

Capital adjustment cost is modeled as a quadratic function of the current and past capital stock level and it captures the fact that faster adjustments in the capital stock are more expensive:

$$
\Phi\left(K_{t+1}, K_{t}\right)=\frac{\phi}{2}\left(\frac{K_{t+1}}{K_{t}}-\mu\right)^{2}
$$

The production function is assumed to be Cobb-Douglas, where $\Gamma_{t}$ allows for labor augmenting productivity growth and $\alpha$ represents the share of labor in total income:

$$
F\left(K_{t}, \Gamma_{t} h_{t}\right)=K_{t}^{1-\alpha}\left(\Gamma_{t} h_{t}\right)^{\alpha}
$$

Finally, the trade balance to output ratio is defined as:

$$
T B Y_{t}=\frac{Y_{t}-C_{t}-I_{t}}{Y_{t}}
$$

\footnotetext{
${ }^{12}$ Cobb-Douglas preferences are also widely used but, as Neumeyer and Perri (2005) show, they have poorer modeling performances in replicating emerging market stylized fact than GHH preferences.
} 
In order to get the model to the data, a log-linear solution to the stationarized version of the model has to be derived. Therefore we proceed in the following way: (1) we stationarize the model by detrending all the variables which exhibit long run growth (2) then we derive the first order conditions, which characterize the optimal behavior of the two types of agents in the economy (3) finally, we log-linearize the optimality conditions around the steady state of the model. The resulting linear rational expectation system of difference equations which fully characterizes the optimal dynamics of the state and control variables was solved in Matlab.

\section{B.3. Calibration and estimation}

In order to solve the linear rational expectation system of difference equations, which fully characterizes the optimal dynamics of the model economy, values to the model parameters must be assigned. We do this in two different ways: we estimate, by using Bayesian techniques, a set of parameters which are considered in the literature as being country specific or difficult to calibrate, and we calibrate the rest of the parameters.

\section{B.3.1 Calibrated parameters}

We set the value of the calibrated parameters based on long averages provided by macroeconomic data in the case of each country ${ }^{13}$, or we set them to values commonly used in emerging market business cycle literature. These are presented in Table C.1 for each

\footnotetext{
${ }^{13}$ The last section of this appendix presents the source of this data.
} 
country:

\begin{tabular}{|l|c|c|c|c|c|}
\hline \hline & Bulgaria & The Czech Republic & Hungary & Poland & Romania \\
\hline \hline$\alpha$ & 0.6742 & 0.6012 & 0.6097 & 0.6820 & 0.6428 \\
$\delta$ & 0.025 & 0.025 & 0.025 & 0.025 & 0.025 \\
$\sigma$ & 2 & 2 & 2 & 2 & 2 \\
$\tau$ & s.t. $\bar{h}$ & s.t. $\bar{h}$ & s.t. $\bar{h}$ & s.t. $\bar{h}$ & s.t. $\bar{h}$ \\
$\omega$ & 1.6 & 1.6 & 1.6 & 1.6 & 1.6 \\
$\beta$ & 0.98 & 0.98 & 0.98 & 0.98 & 0.98 \\
$\mu$ & 1.0130 & 1.0106 & 1.0071 & 1.0110 & 1.0151 \\
$\bar{r} *$ & 1.0039 & 1.0039 & 1.0039 & 1.0039 & 1.0039 \\
$\bar{d}$ & 0.4457 & 0.1703 & 0.7617 & 0.3545 & 0.3145 \\
$\bar{h}$ & 0.3877 & 0.4665 & 0.3912 & 0.3828 & 0.4385 \\
\hline \hline
\end{tabular}

Table C.1. Calibrated Model Parameters

The labor share of income, $\alpha$, is set at the ten years average of the compensation of labor input to value added ratio in the case of each country. The rate of capital depreciation, $\delta$, is 0.025 , which would imply a $10 \%$ annual depreciation rate and which is commonly used in emerging market business cycles papers. The preference parameters are set as follows: the coefficient of relative risk aversion, $\sigma$, defining the curvature of the utility function is $2 ; \omega$, the exponent of labor in the utility function is 1.6 and the weight of labor in the per period utility, $\tau$, is set such that it implies that households allocate $\bar{h}$ share of their total time to working. These definitions and parameterizations are in line with those assumed by Schmidt-Grohe and Uribe (2003), Neumeyer and Perri (2005), Garcia-Cicco et al. (2010) and others. $\beta$ discount factor is set at 0.98 which would imply a $2.04 \%$ quarterly risk free real interest rate.

The long run productivity growth, $\mu$, is defined as average real GDP growth rate over the period 2000-2009 ${ }^{14}$. The steady state level of gross foreign interest rate, $\bar{r}^{*}$, is computed as the quarterly average of the Euro Zone real interest rate over 2000-2009 period. $\bar{d}$, the long run external debt to GDP ratio, is proxied as the 1997-2007 average of the net foreign asset to GDP ratio. The steady state share of labor, $\bar{h}$, is defined as the ten years average employment to total population ratio.

\footnotetext{
${ }^{14}$ This type of association between parameter and statistical definition is used by Aguiar and Gopinath (2007a) in the case of Argentina and than it was taken over by other papers, e.g. Aguiar and Gopinath (2007b), Chang and Fernandez (2009).
} 


\section{B.3.2 Estimated parameters}

We use Bayesian techniques as proposed by Smets and Wouters (2003), Lubik and Schorfheide (2005) and An and Schorfheide (2007) over the sample period 1995Q1:2009Q4 in order to estimate those parameters which are country specific (e.g. working capital parameter, capital adjustment cost coefficient) or difficult to calibrate (e.g. the persistence and standard deviation of different shocks, the elasticity of country spread with respect to the Solow residual). These authors argue that the main advantage of the Bayesian estimation of DSGE models in comparison with moment or impulse response matching is that the parameters are seen as random variables, and a prior density which incorporate initial beliefs and information about these parameters is specified together with a likelihood function for the DSGE model. Based on these, the posterior mode of each parameter can be computed and by using Bayes theorem to update initial beliefs, the conditional distribution of each parameter (i.e. posterior distribution) is calculated given the observable variables (i.e. data) and the model. An and Schorfheide (2007) point out that the main benefit of this posterior distribution consists of the fact that it permits to perform inference concerning the parameters and to conduct a likelihood based checking of the goodness of fit.

Basically, this is a two step procedure: (1) in the first step the posterior mode is computed by using an optimization routine to find that value of the parameters which minimizes the negative log-likelihood given the model, the data based on which we perform the estimation and prior probability distribution of the parameters to be estimated. ${ }^{15}$ The inverse of the Hessian of the log-likelihood function is evaluated at the optimal posterior mode. (2) The second step consists of running a Markov Chain Metropolis-Hastings (MCMH) algorithm which constructs a Gaussian approximation around the posterior mode in the following way: it draws a number from a normal distribution characterized by mean equal to the posterior mode obtained in the previous step and variance-covariance matrix set at the inverse of the log-likelihood function evaluated at the same posterior mode and scaled up by a constant (i.e. jumping distribution). Then it decides whether to accept this newly drawn value as the mean of the jumping distribution used for the next draw with a certain probability (i.e. acceptance ratio computed as the ratio between the log-likelihood of the model evaluated at the newly drawn parameter and the same likelihood evaluated at the parameter value obtained from the previous draw) or to continue with the parameter value obtained from the previous draw, with probability one minus the acceptance ratio. The more these draws are repeated the more efficiently and effectively the algorithm can explore the posterior

\footnotetext{
${ }^{15}$ To find the optimal value of the posterior mode we use a Monte-Carlo based optimization routine, with 100000 simulations, implemented in Dynare. This turned out to be a more robust method than solving a simple constrained minimization problem.
} 
distribution in the neighborhood of the posterior mode.

Therefore three main ingredients are needed to implement the above described procedure: the model, the observable variables and the definition of the prior distribution of the estimated parameters. Firstly, the model has to be written in a linear rational expectation system form which is solved by using numerical methods. ${ }^{16}$ Then the model is written in state space form together with the measurement equations while its likelihood is computed by using the Kalman filter.

Secondly, the observable variables must be defined and fed into the model. We use four observable variables because they are available in the case of all countries and the methodology based on which they are collected should not differ across countries. These are the HP filtered quarterly gross domestic product $(o b s Y)$, consumption $(o b s C)$ and investment (obsINVE) taken in logarithm and HP filtered trade balance to output ratio (obsTBY) over the period 1995:1-2009:4. We assume that these observables are subject to measurement errors because of two reasons. One reason is technical in nature, and it aims to overcome the stochastic singularity problem, i.e. the number of structural shocks in the model must be equal to the number of observables considered for the estimation. Since in the present models there are three, respectively four shocks, at least one measurement error must be included while estimating the uniform interest rate and non-persistent country spread version of the model or at least two measurement errors have to be defined when estimating the uniform interest rate and persistent country spread extension. We assume that the measurement errors $\left\{\epsilon_{o b s Y}, \epsilon_{o b s C}, \epsilon_{o b s I}, \epsilon_{o b s T B Y}\right\}$ follow i.i.d. processes with zero mean and $\sigma_{z 2=\left\{\epsilon_{o b s Y}, \epsilon_{o b s C}, \epsilon_{o b s I}, \epsilon_{o b s T B Y}\right\}}$ standard deviation. The other reason for defining measurement errors is related to the potential role they play in conducting robustness check of the results. Therefore, when estimating the model we distinguish two cases: estimation without measurement errors, when we augment the state space just by as many measurement errors as many are needed to overcome the stochastic singularity problem, versus estimation with measurement errors, when we consider that all the observables contain measurement error. By considering that macroeconomic data usually contain errors and omissions because of aggregation, changes in methodologies, definitions, rules and regulations applied during collecting them the inclusion of measurement errors should improve the estimation results if the errors are indeed influential.

Finally, the prior distribution is usually subjective because it describes uncertainty and prior knowledge about the model and its parameters. We select the shape of the distribution

\footnotetext{
${ }^{16}$ For this we use perturbation methods implemented in Dynare toolbox which provide as a solution a linear dynamic version of the model which contains the dynamics of the state and control variables, i.e. policy functions.
} 
based on those applied in earlier papers on emerging market business cycles and based on the restrictions regarding possible domain of definition of different parameters. The expected value and standard deviation of each distribution assumed are set at values provided by macroeconomic data. Overall, we estimate eleven structural parameters, as reported in Table 5 which can be divided into two groups.

$\begin{array}{llcc}\text { Parameter } & \text { Prior shape } & \text { Expected value } & \text { Std. dev. } \\ \sigma_{z 1} & \text { Gamma } & 0.2 & 0.1 \\ & \text { Inverse Gamma } & 0.2 & \text { Inf } \\ \rho_{a} & \text { Beta } & 0.9 & 0.01 \\ \rho_{g} & \text { Beta } & 0.72 & 0.01 \\ \rho_{r^{*}} & \text { Beta } & 0.8 & 0.01 \\ \eta & \text { Gamma } & 0.5 & 0.1 \\ \psi & \text { Gamma } & 0.15 & 0.05 \\ \phi & \text { Gamma } & 6 & 2 \\ \theta & \text { Beta } & 0.5 & 0.1 \\ \sigma_{z 2} & \text { Gamma } & 0.02 & 0.01 \\ & \text { Inverse Gamma } & 0.02 & \text { Inf }\end{array}$

Table C.2 Prior Distribution of the Estimated Model Parameters

The first group contains the persistence and the standard deviation of the shock processes. In line with previous studies, we assume that the persistence of the $A R(1)$ shock processes follow Beta distribution because this distribution is the most suitable for parameters taking values between zero and one. The standard deviation of this distribution is harmonized across different shocks and it is set at 0.01 while the mean of the distribution differs across shocks. Since the transitory technology shock is documented in the literature as persistent (e.g. Smets and Wouters, 2007; Chang and Fernandez, 2009; Garcia-Cicco et al., 2010), we set the mean of the distribution of $\rho_{a}$ to 0.9 ; the mean of the persistence of permanent technology shock, $\rho_{g}$, is set at 0.72 since previous estimation results reported in the RBC literature suggests that it is less persistent than the transitory one; quantitative macroeconomic literature provides a series of evidences that US and Euro Zone real interest rates are both highly persistent or they follow an almost random walk process. Uribe and Yue (2006) estimate an $\mathrm{AR}(1)$ process on the 3-month real gross Treasury bill rate and they obtain a significant point estimate of the persistence parameterequal to 0.83. Similarly, Lubik and Schorfheide (2005) estimate the same parameter and get 0.84 in the case of the US and 0.83 in the Eurozone. Thus, we set the mean of the distribution of $\rho_{r^{*}}$ at 0.8 while 
the distribution of the persistence of country spread is assumed to have mean 0.65 in line with the autocorrelation coefficient of the EMBI spread reported in the first section of the paper.

The distribution of the standard deviation of the shock processes $\left(\sigma_{z 1=\left\{\epsilon_{a}, \epsilon_{g}, \epsilon_{r^{*}}, \epsilon_{s}\right\}}\right)$ is considered being the same across different types of shocks. Generally, in the quantitative macro literature dealing with Bayesian estimation of DSGE models, standard errors of shocks are assumed to follow inverse gamma distribution mainly because this is a sensible distribution to relative shock sizes ${ }^{17}$. Moreover, gamma distribution could be another good candidate for the distribution followed by these standard deviations because it is used in the case of parameters which take positive values. Thus, we estimate each specification of the model by considering two cases: first, we assume that the standard deviation of the shocks follows gamma distribution with mean 0.2 and standard deviation 0.1 , while, in the other case, we consider inverse gamma distribution with mean 0.1 and scale parameter infinity.

The second group of structural parameters consists of those parameters which characterize financial decisions in the model. These are the elasticities of country spread with respect to Euro Zone interest rate, $\eta_{r^{*}}$, and Solow residual, $\eta_{S R}$. Since with the exception of $\eta_{S R}$ in the case of Argentina there are no previous evidences concerning the Bayesian estimation of these parameter we assume that they follow Gamma distribution (i.e. they take positive values because it is intuitive to assume that country spread increases as Euro Zone interest rate gets higher or when a negative productivity shock hits the economy) with mean 0.5 and standard deviation 0.1. The mean of the distribution was set based on the observed correlation coefficient between EMBI spread and Euro Zone interest rate, on the one hand, and EMBI spread and output, on the other hand.

Another financial parameter of the model is the debt-elastic interest rate parameter, $\psi$, which measures the sensitivity of interest rate/country spread to fluctuations in external debt position. This parameter is usually not estimated and is calibrated at 0.001 , value which was proposed by Mendoza (1991) in the case of the Canadian economy. Garcia-Cicco et al. (2010) are the only authors who estimate this parameter, assuming that it follows uniform distribution. Thus it is worth to pay particular attention to this parameter and estimate it because it could easily happen that in the case of emerging economies the data would attribute a higher value to it. Logically it can be expected that country spread is more sensitive to movements in debt position in emerging economies than in developed countries; hence calibrating it to 0.001 would be erroneous. We assume that this parameter follows a gamma distribution with mean 0.15 and standard deviation 0.05 . This is a rather loose prior

\footnotetext{
${ }^{17}$ For a detailed description of the most frequently used distributions in DSGE Bayesian estimation, advantages and shortcomings of them consult Ermolaev et al. (2008): Estimating GPM with Dynare mimeo.
} 
but since there is no previous evidence on estimating it, the prior should take into account this uncertainty (i.e. this is why the standard deviation of the distribution takes relatively high value).

Because the capital adjustment cost parameter, $\phi$, is a positive parameter it is assumed to follow a gamma distribution with mean 6 and standard deviation $2 .{ }^{18}$ This is a somewhat tighter prior than those assumed by Chang and Fernandez (2009) who estimate $\phi$ by considering that it follows a gamma $(3,2)$ distribution in the case of Mexico or Smets and Wouters (2007) who assume normal $(1.25,0.24)$ in the case of Eurozone. However, this is in line with Garcia-Cicco et al. (2010) who consider gamma(8,4) distribution. The working capital constraint, $\theta$, parameter takes values between zero and one, thus we assume that it follows Beta distribution with mean 0.5 and standard deviation 0.1. The main motivation for setting the mean of this parameter to 0.5 is provided by the data which suggests that the cross country average of the short run private credit of non-financial corporations to value added ratio is around 0.45 . This assumption is similar to those made by Chang and Fernandez (2009).

Finally there is a set of nonstructural parameters which consists of the standard deviation

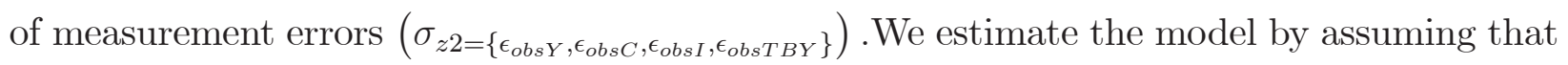
these parameters follow: inverse gamma with mean 0.02 and scale parameter set to infinity or gamma distribution with mean 0.02 and standard deviation 0.01 . This is a wide prior, but in this way uncertainty concerning the values of these standard deviations can be incorporated into the prior knowledge.

We set the algorithm to make one hundred thousand draws ${ }^{19}$; the initial $50 \%$ of draws were dropped out to ensure that the results do not depend on the initial value, and the scaling parameter in the jumping distribution was fine tuned (around 0.4) such that to obtain approximately one third acceptance ratio. Moreover, in order to conduct convergence diagnostic (i.e. ensure that two different chains converge to the same stationary distribution) we run two parallel Markov Chains and check the presence of convergence by comparing recursively computed second order moments ${ }^{20}$ of the distributions constructed under each

\footnotetext{
${ }^{18}$ We estimated the model by assuming a loose prior for the distribution of $\phi$ like gamma $(3,2)$ for the first time and then we systematically tightened the prior by increasing the mean of the distribution. It turned out that indifferently of how tight or loose the prior is the data and the model had the tendency to push up the posterior mode of $\phi$ to values around 6 across all the countries. Hence we set the mean at 6 in order to obtain a better fit.

${ }^{19}$ Initially, we set the number of draws to half a million in the MCMH algorithm but due to the robustness of the optimization method used in the first step the two chains started to converge fast after 20000 draws. We checked if this convergence is present in the case of all the five countries by estimating the Chang and Fernandez (2009) version of the model with both 100000 and half a million draws. The estimation results and the convergence statistics confirmed that 100000 draws are enough to achieve convergence.

${ }^{20}$ These second order moments are the variance of the distribution, skewness and confidence interval
} 
and every draw per chain.

The estimation results can be summarized as follows: (1) The goodness of fit statistics indicate that the specification which fits the best the data assumes gamma distribution for the standard deviations of the shocks, all the observable variables contain measurement errors and the parameter $\psi$ is estimated in the case of all the five sampled countries, (2) The point estimates of $\psi$ suggest that it is erroneous to calibrate the debt elastic interest rate parameter to 0.001, as proposed by Mendoza (1991) and as it has been used so far in the literature. The data suggests that, given the considered model setup, $\psi$ varies in [0.02, 0.23] interval across countries and across different model specifications, (3) The posterior means of the persistence and standard deviation parameters of the shocks are relatively stable across different model specifications, and (4) Financial parameters (like the elasticity of country spread, working capital constraint or capital adjustment cost parameter) vary slightly across different model versions. In addition, a certain degree of heterogeneity in the point estimates of these financial parameters can be observed across countries. The rest of this subsection discusses these results in more details.

When the debt elastic interest rate parameter, $\psi$, is not estimated, the estimates of financial parameters ${ }^{21}$, especially that of the capital adjustment cost parameter changes significantly, as reported in Table C.3. Independently of the model version considered, by calibrating $\psi$ to 0.001 , as proposed by Mendoza (1991), the estimate of the capital adjustment cost parameter becomes more than double in comparison with the case when $\psi$ is estimated. In addition, the elasticity of country spread and the working capital constraint parameter increase.

$\begin{array}{llllll}\psi & \text { Bulgaria } & \text { Czech Rep. } & \text { Hungary } & \text { Poland } & \text { Romania } \\ \text { Calibrated to 0.001 } & 17.29 & 13.14 & 13.62 & 14.22 & 14.68 \\ \text { Estimated } & 7.93 & 7.79 & 6.48 & 4.99 & 7.61\end{array}$

Table C.3. Posterior mean of $\phi$ under different specification of $\psi$

This result is not counterintuitive at all and it actually underlines the role of capital adjustment cost in the model. When $\psi$ is calibrated to a low value relative to what the data would imply the interest rate is less sensible to large movements in external debt, i.e. external financing is relatively cheap. Consequently, agents would like to adjust even more their capital stock by using besides their own funds more external financing, generating in this way higher investment volatility. In order to limit this investment volatility, the cost of constructed around the parameter mean.

${ }^{21}$ For example, the elasticity of country spread with respect to the Solow residual and Euro Zone interest rate or the working capital constraint parameter. 
an additional unit of capital accumulated must be higher, i.e. the capital adjustment cost parameter must increase.

For example, Chang and Fernandez (2009) calibrate $\psi$ instead of estimating it and they obtain a point estimate of $\phi$ equal to 14.72 in the case of Argentina. This result is similar to those we report in Table C.3 suggesting two digit numbers for $\phi$ across all the countries when $\psi$ is calibrated. However, when $\psi$ is estimated its point estimates vary in $[0.02,0.23]$ interval depending on country, model and prior specification. These are somewhat lower estimates than the $\psi$ equal to 2.8 reported by Garcia-Cicco et al. (2010). This indicates that the data shifts the posterior mode of the conditional distribution upper, to the right in the distribution of the parameter, suggesting that the external debt elasticity of country spread or interest rate in the case of CEECs might be higher than 0.001, i.e. country spread or interest rate is more sensitive to changes in the external debt position in CEECs than in developed ones, like Canada.

Regarding the estimates of $\phi$ reported in Table C.3, one can observe that $\phi$ takes values between 3.4 and 8.2 when $\psi$ is estimated. These results are not at odds neither with the previous evidences in RBC literature nor with the existing empirical evidences obtained from research on investment behavior. For example Cummins et al. (2006) estimate $\phi$ by using cross section data of firms from the US and conclude that the estimated $\phi$ is about 7.2 in the US. Thus, the estimates of $\phi$ obtained both in the case of the uniform interest rate model and the persistent spread model are quite plausible. To motivate lower estimates of $\phi$, one can use the figures reported by Aguiar and Gopinath (2007a) who obtain estimates for $\phi$ between 2.82 and 3.79 by using moment matching, or those recently documented by Garcia-Cicco et al. (2010) (i.e. they estimate $\phi$ at 4.6 in the case of Argentina by using Bayesian techniques).

\section{Data Appendix}

1. National account components from Eurostat (quarterly frequency): the following components measured in millions of national currency chain-linked volumes (reference year 2000) are used in the paper (with the corresponding identification code in the brackets):

1.1. Output: gross domestic product at market prices (B1GM) series

1.2. Consumption: household and NPISH final consumption expenditure (P31_S14_S15):

1.3. Investment: gross fixed capital formation (P51)

1.4. Exports: exports of goods and services (P6)

1.5. Imports: imports of goods and services (P7)

1.6. Trade balance to output ratio: is the ratio between net exports, computed as the difference between exports of goods and services (P6) and imports of goods and services 
(P7), and gross domestic product at market prices (B1GM)

weseasonally adjusted of all the above presented series by using Tramo-Seats method implemented in Demetra 2.1. software package.

Cyclical components (logarithmic deviation from the long run trend) of the seasonally adjusted output, consumption investment and trade balance to GDP ratio: are computed in three steps (i) firstly, the above described level series are taken in logarithm (ii) the time series, obtained in this way, are filtered by using Hodrick-Prescott filter with $\lambda=1600$ scale parameter (iii) the cyclical component of each series is computed as a difference between the logged level series and its trend component.

2. Real Euro Zone interest rate (quarterly frequency): is computed as the difference between the overnight German money market rate and annualized quarterly German inflation rate. The source of the interest rate is the Online Historical Financial Statistics published by The Deutsche Bundesbank and it is defined as Frankfurt banks / Overnight money / Monthly average: SU0101, from which the quarterly series is constructed by taking the corresponding monthly rate at the end of each quarter. The annualized quarter-to-quarter inflation rate is computed based on the quarterly consumer price index $(13464 \mathrm{ZF})(2000=100)$ from International Financial Statistics of IMF according to the following formula:

$$
\inf =400 * \ln \left(\frac{C P I_{t, 2000=100}}{C P I_{t-1,2000=100}}\right)
$$

3. Country spread (quarterly frequency): is quantified by using JP Morgan EMBI Global Divers-Stripped spread in Poland (JPMGPOC (SSPRD)) covering the period 1995Q1:2009Q4, in Hungary (JPMGHNC (SSPRD)) over the period 1999Q1:2009Q4 and in Bulgaria (JPMPBUL (BSPRD)), 1994Q3:2009Q4; In order to compute EMBI spread US-dollar denominated Brady bonds, Eurobonds, and traded loans issued or guaranteed by sovereign entities are considered. Only issues with a current face amount outstanding of $\$ 500$ million or more and a remaining life of greater than $21 / 2$ years are eligible for inclusion in the index. ${ }^{22}$ Moreover the yield spread used in the case of Hungary is computed as the absolute difference between yield on long term Eurobonds issued by the Hungarian government (568915(RYAN)) and yield on long term US Treasury bonds. (993766(RYAN)) ${ }^{23}$.

4. Compensation of labor input (annual frequency): (i) total compensation of labor (lab_tot) is obtained from the EU KLEMS database for The Czech Republic, Poland and Romania. This is computed as the sum of compensation for employees and that part of the operating surplus/ mixed income which represents the compensation for self-employed

\footnotetext{
${ }^{22}$ Source: http://www.jpmorgan.com/pages/jpmorgan/investbk/solutions/research/EMBI

${ }^{23}$ Source: Datastream
} 
24 Data concerning mixed income is not available in the case of Bulgaria and Romania (ii) compensation of employees at industry level published by Eurostat in the National Accounts by 6 branches at current prices (nama_nace06_c) and defined as the total remuneration, in cash or in kind, payable by an employer to an employee in return for work done by the latter. Social contributions paid by the employer are also included in this indicator.

5. Value added (annual frequency): (i) total value added in the economy (all industries) at current prices, in millions of euro, is obtained from the EU KLEMS database (va_tot) for Hungary, the Czech Republic and Poland; in the case of Bulgaria and Romania the source of value added is Eurostat (B1G) (ii) industry level value added series, at current prices, in millions of national currency, are from the National Accounts aggregates and employment by branch tables (NACE) (nama_nace) published by Eurostat.

6. Private credit of non-financial corporations (annual frequency): since there are no publicly available figures concerning the type of loans besides their maturity for the Czech Republic, Hungary and Romania, short term financial liabilities (stocks) of non-financial corporations in millions of national currency, from the Czech National Bank's, the National Bank's of Hungary and the Romanian National Bank's Monetary and financial statistics, are taken as proxy for working capital loans; working capital loans to non-financial private corporations (stocks) in millions of national currency is considered in the case of Poland published by the National Bank of Poland in the Monetary and financial statistics: Assets and liabilities of monetary financial institutions; Bulgaria: there is no publicly available data.

7. Real GDP growth rate (quarterly frequency): measured as the percentage change of the gross domestic product at constant prices relative to the previous period from the GDP and main components-volumes (namq_gdp_k) table published by Eurostat

8. Net Foreign Asset (NFA) position (annual frequency): in millions of US dollars is from the updated and extended version of dataset constructed by Lane and Milesi-Ferretti (2007) in the "External Wealth of Nations" Dataset, 1970-2007

9. Gross Domestic Product (annual frequency): is at current prices, in millions of US dollars from the updated and extended version of dataset constructed by Lane and MilesiFerretti (2007) in the "External Wealth of Nations" Dataset, 1970-2007 ${ }^{25}$

10. Employment: (annual frequency): measured as annual average total employment (1564 years, resident population concept - LFS) in thousand of persons from the Employment (main characteristics and rates) (lfsi_emp_a ) table published by Eurostat.

11. Population: is in thousand of persons and it is obtained from Population, activity

\footnotetext{
${ }^{24}$ For more details see EU KLEMS Growth and Productivity Accounts Version 1.0 Methodology, March 2007 http://www.euklems.net/

${ }^{25}$ More details about the source of the data at http://www.philiplane.org/EWN.html
} 
and inactivity - Annual averages (lfsi_act_a) table, Eurostat. 


\section{Graphs and Tables}

D.1. Results of the simulation of the small open economy RBC model with endogenous country spread (initial external debt above and capital below their steady stateby 10\%)

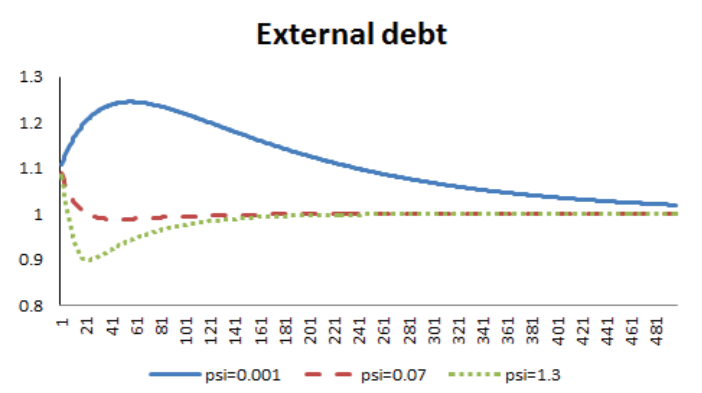

Country spread

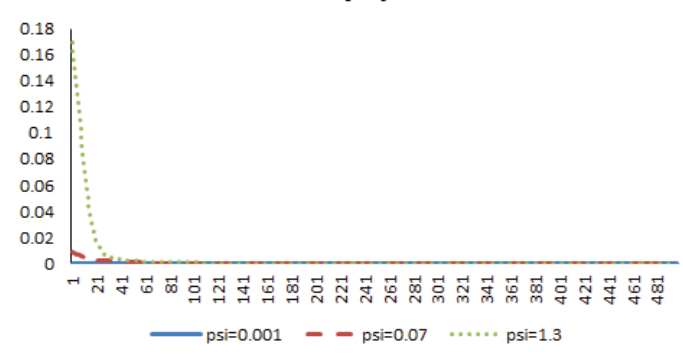

Trade balance

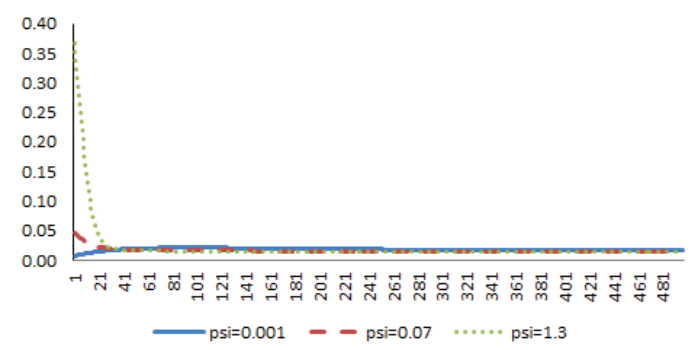

Utility

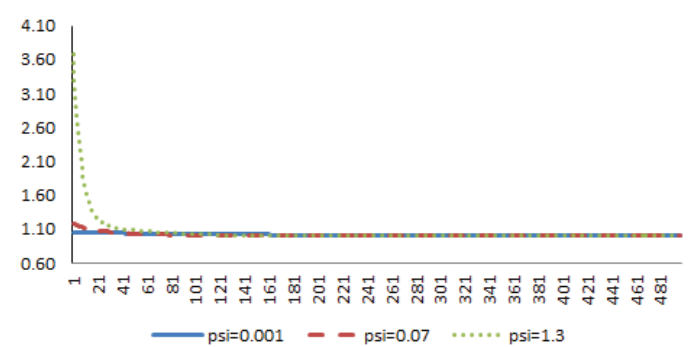

Capital stock

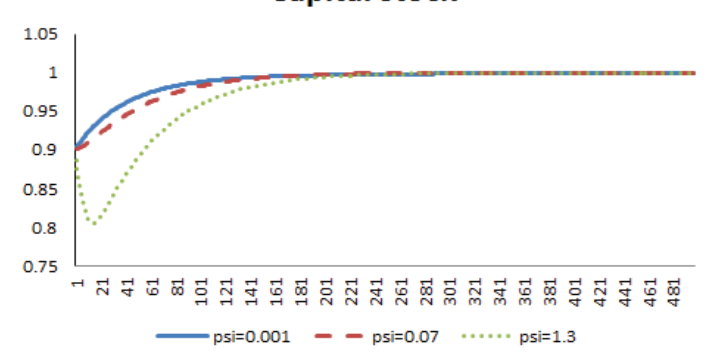

Current account

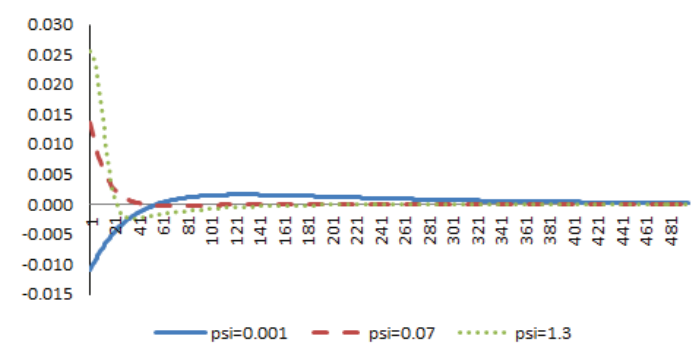

Consumption per capita

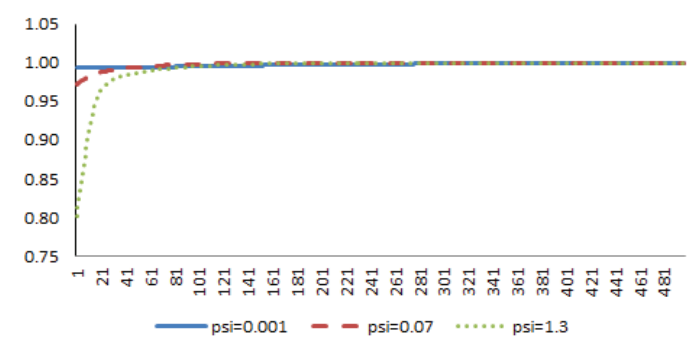

